\title{
Changes in chemical components of aerosol particles in different haze regions in China from 2006 to 2013 and contribution of meteorological factors
}

\author{
X. Y. Zhang, J. Z. Wang, Y. Q. Wang, H. L. Liu, J. Y. Sun, and Y. M. Zhang \\ Key Laboratory of Atmospheric Chemistry, Institute of Atmospheric Compositions, Chinese Academy of Meteorological \\ Sciences, CMA, 46 Zhong Guan Cun S. Ave., Beijing 100081, China
}

Correspondence to: X. Y. Zhang (xiaoye@cams.cma.gov.cn)

Received: 29 May 2015 - Published in Atmos. Chem. Phys. Discuss.: 13 July 2015

Revised: 24 October 2015 - Accepted: 29 October 2015 - Published: 22 November 2015

\begin{abstract}
Since there have been individual reports of persistent haze-fog events in January 2013 in central-eastern China, questions on factors causing the drastic differences in changes in 2013 from changes in adjacent years have been raised. Changes in major chemical components of aerosol particles over the years also remain unclear. The extent of meteorological factors contributing to such changes is yet to be determined. The study intends to present the changes in daily based major water-soluble constituents, carbonaceous species, and mineral aerosol in $\mathrm{PM}_{10}$ at 13 stations within different haze regions in China from 2006 to 2013, which are associated with specific meteorological conditions that are highly related to aerosol pollution (parameterized as an index called Parameter Linking Aerosol Pollution and Meteorological Elements - PLAM). No obvious changes were found in annual mean concentrations of these various chemical components and $\mathrm{PM}_{10}$ in 2013, relative to 2012. By contrast, wintertime mass of these components was quite different. In Hua Bei Plain (HBP), sulfate, organic carbon (OC), nitrate, ammonium, element carbon (EC), and mineral dust concentrations in winter were approximately 43, $55,28,23,21$, and $130 \mu \mathrm{g} \mathrm{m}^{-3}$, respectively; these masses were approximately 2 to 4 times higher than those in background mass, which also exhibited a decline during 2006 to 2010 and then a rise till 2013. The mass of these concentrations and $\mathrm{PM}_{10}$, except minerals, respectively, increased by approximately 28 to $117 \%$ and $25 \%$ in January 2013 compared with that in January 2012. Thus, persistent haze-fog events occurred in January 2013, and approximately $60 \%$ of this increase in component concentrations from 2012 to 2013 can be attributed to severe meteorological conditions in the
\end{abstract}

winter of 2013. In the Yangtze River Delta (YRD) area, winter masses of these components, unlike HBP, have not significantly increase since 2010; PLAM were also maintained at a similar level without significant changes. In the Pearl River Delta (PRD) area, the regional background concentrations of the major chemical components were similar to those in the YRD, accounting for approximately $60-80 \%$ of those in HBP. Since 2010, a decline has been found for winter concentrations, which can be partially attributable to persistently improving meteorological conditions and emission cutting with an emphasis on coal combustion in this area.

In addition to the scattered and centralized coal combustion for heating, burning biomass fuels contributed to the large increase in concentrations of carbonaceous aerosol in major haze regions in winter, except in the PRD. No obvious changes were found for the proportions of each chemical components of $\mathrm{PM}_{10}$ from 2006 to 2013. Among all of the emissions recorded in chemical compositions in 2013, coal combustion was still the largest anthropogenic source of aerosol pollution in various areas in China, with a higher sulfate proportion of $\mathrm{PM}_{10}$ in most areas of China, and OC was normally ranked third. $\mathrm{PM}_{10}$ concentrations increased by approximately $25 \%$ in January of 2013 relative to 2012, which caused persistent haze-fog events in HBP; emissions also reduced by approximately $35 \%$ in Beijing and its vicinity (BIV) in late autumn of 2014, thereby producing the Asia Pacific Economic Cooperation (APEC) blue (extremely good air quality); thus, one can expect that the persistent haze-fog events would be reduced significantly in the BIV, if approx. one-third of the 2013 winter emissions were reduced, which 
can also be viewed as the upper limit of atmospheric aerosol pollution capacity in this area.

\section{Introduction}

From a satellite-based aerosol optical depth, ambient fine particulate matter concentrations were found to have a high loading area, with China being a major global contributor (Donkelaar and Villeneuve, 2010). Globally, mass concentrations of six major types of chemical components in aerosol particles in China were also found to be just lower than those in the urban southern Asian area but far higher than those in Europe and North America (X. Y. Zhang et al., 2012), with a large variation in time and space (Zhang et al., 2008; He et al., 2001; Hu et al., 2002; Yao et al., 2002; Ye et al., 2003; Zhang et al., 1993, 2002; Li et al., 2014; Xu et al., 2014; Yin et al., 2012). Moreover, approximately 37.5 billion tons of standard coal are consumed as an energy source in China; approximately $66 \%$ of the produced energy was attributed to coal consumption in 2013 (NBS-China, 2014). Since the aerosol particles and cloud (fog) droplets can influence atmospheric visibility (Watson, 2002), and in the ambient atmosphere no cloud (fog) can be formed if no hygroscopic aerosols can be activated to cloud condensation nuclei (CCN) or ice nuclei (IN) (Twomey, 1977; Seinfeld and Pandis, 1997), high loadings of aerosols not only affect climate change (Forster et al., 2007; Boucher et al., 2013) but also adversely influence weather (Wang et al., 2010; Pérez et al., 2006) and contribute to the occurrence of haze and fog events, both of which can be considered as types of aerosol pollution in present-day China (Zhang et al., 2013). Since there have been individual reports of persistent haze-fog events in January 2013 in central-eastern China, the change in aerosol particles and their chemical components are attracting special attention in this rapid economic growth and high population density area (H. Wang et al., 2014; X. Wang et al., 2014; Z. Wang et al., 2014; Wang et al., 2015; Huang et al., 2014; Zhang et al., 2013; Guo et al., 2014; Sun et al., 2014). However, questions were raised about what changes occurred to the major chemical components of aerosol in different haze areas in China during recent years, as well as why a big difference existed between 2013 and an adjacent year in the case of no significant changes in emission. What extent of meteorological factors contributed to the change?

China can be classified into nine typical regions with similar visibility changes in each (X. Y. Zhang et al., 2012); four of these regions have experienced the largest loss of visibility in recent decades, particularly (1) Hua Bei Plain in North China and Guanzhong Plain; this region includes Jing-JinJi a.k.a. the Beijing-Tianjin-Hebei (BTH) region with rapid economic development; this area is also considered haze region II in China; (2) East China with the main body in the Yangtze River Delta area (haze region III); (3) South China comprising Guangdong and the Pearl River Delta area (haze region V); and (4) Si Chuan Basin in Southwest China (haze region VI) (Fig. 1). Changes in major chemical components of aerosol in these different haze areas also remain unknown. These changes are also important for exploring the reasons for the occurrence of severe haze-fog in China in recent years.

Various meteorological factors, including wind speed, wind direction, air pressure, temperature, humidity, precipitation, and atmosphere stability, are possibly related to aerosol pollution, but each meteorological factor cannot completely and quantitatively indicate the integrated situation of meteorological conditions that may aggravate aerosol pollution (Sui et al., 2007; Pang et al., 2009). However, mechanisms by which these meteorological impacts can be quantified and by which these data can be used to diagnose aerosol pollution are based on a longer timescale of emission changes than meteorological factors (Wang et al., 2012; Yang, 2009).

Long-term daily based aerosol chemical components were determined here for aerosol particles with a diameter of less than $10 \mu \mathrm{m}\left(\mathrm{PM}_{10}\right)$ from regionally representative measurement networks (China Atmosphere Watch Network CAWNET) from 2006 to 2013. The parameterized index (Parameter Linking Aerosol Pollution and Meteorological Elements - PLAM) (Wang et al., 2012; Yang, 2009) was also used in this study to evaluate specific meteorological conditions and their connections with severe aerosol pollution. This study investigates the changes and the extent of these changes by analyzing chemical component changes and meteorological factors; this study also determined the relative contribution of specific meteorological conditions in winter. These chemical component data, especially in 2012 and 2013, can also be used as a basis to evaluate various control measures that have been used. After 2013, the Chinese government promoted 10 prevention measures and countermeasures for aerosol pollution control called Atmospheric Pollution Prevention and Control of the Ten Measures of China. The government also released the Second Atmospheric Pollution Control Special Plan. All of these have gained increasing attention among researchers to reduce emissions caused by aerosols with an emphasis on coal combustion and industrial manufacturing processes, mainly in steel mills, chemical plants, and glass and cement plants. The long-term chemical characterization of aerosols in China is also essential to assess the effect of aerosols in the atmosphere and climate, and the results can be used to evaluate and improve existing haze-fog forecasting systems. 


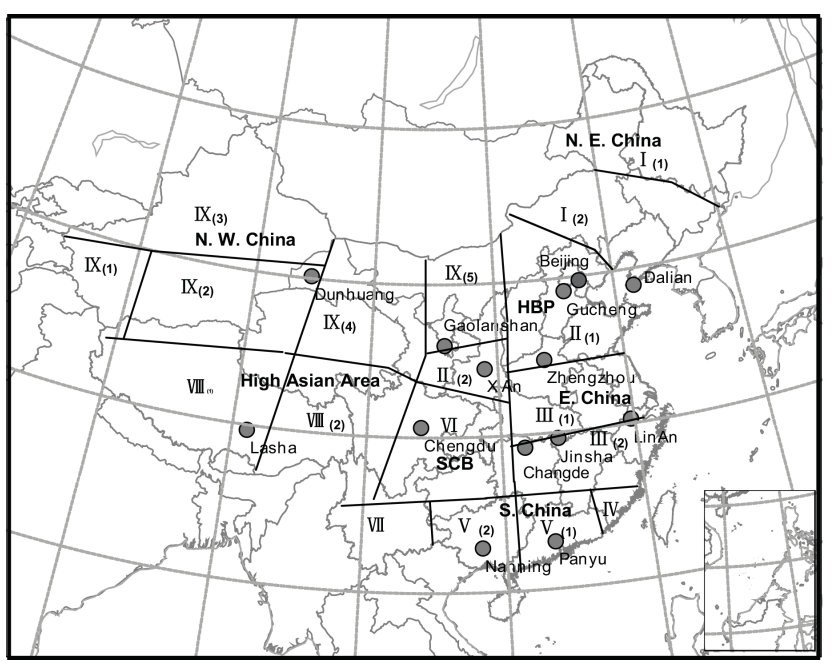

Figure 1. Locations of thirteen CAWNET stations and nine similar visibility changing regions in China (X. Y. Zhang et al., 2012).

\section{Sample collection and analyses}

\subsection{Sampling description}

At 13 CAWNET stations, $24 \mathrm{~h}$ aerosol filter samples were collected on a 1 day in every 3-day basis from 2006 to 2013. These CAWNET stations are operated by the China Meteorological Administration (CMA), as shown in Fig. 1 and the details of these stations have been reported in previous studies (Zhang et al., 2008; X. Y. Zhang et al., 2012). Aerosol samples were collected by using a MiniVol ${ }^{\mathrm{TM}}$ air sampler (Airmetrics, Oregon, USA) operated at an ambient airflow rate of $5 \mathrm{~L} \mathrm{~min}^{-1}$ for 24 $\mathrm{h}$ from 9:00 to 9:00 (British Summer Time - BST) the following day. The filtration media were $47 \mathrm{~mm}$ Whatman quartz microfiber filters (QM/A) that were cleaned by heating at $800^{\circ} \mathrm{C}$ for $3 \mathrm{~h}$ before use.

\subsection{Aerosol chemical component analyses}

The elemental concentrations were analyzed directly via the X-ray fluorescence (XRF) method using X-Lab 2000 (SPECTRO, Germany) at the Key Laboratory for Atmospheric Chemistry, Chinese Academy of Meteorological Sciences (LAC-CAMS). Indeed, 18 elements, namely, $\mathrm{As}, \mathrm{Br}, \mathrm{Ca}, \mathrm{Cr}$, $\mathrm{Cu}, \mathrm{Fe}, \mathrm{K}, \mathrm{Mg}, \mathrm{Mn}, \mathrm{Na}, \mathrm{Ni}, \mathrm{Pb}, \mathrm{S}, \mathrm{Se}, \mathrm{Ti}, \mathrm{V}, \mathrm{Zn}$, and $\mathrm{Zr}$ were analyzed using a multi-channel analyzer that was calibrated using a standard plastic sample to check the signal energy and the multi-channel twice a month. The XRF spectrometer includes a high-tech detector using a silicon lithium drifted crystal cooled at a low temperature $\left(-90^{\circ} \mathrm{C}\right)$. This crystal is able to discriminate between $\mathrm{X}$-ray photons of different energies, i.e., energy dispersion. Four different targets (Mo, $\mathrm{Co}, \mathrm{Al}_{2} \mathrm{O}_{3}$, and highly oriented pyrolytic graphite - $\mathrm{HOPG}$ ) with different energy are employed to identify different elements. For the Mo target, the energy range is $25 \mathrm{keV}$, which is suitable for $\mathrm{Cr}, \mathrm{Mn}, \mathrm{Fe}, \mathrm{Co}, \mathrm{Ni}, \mathrm{Cu}, \mathrm{Zn}, \mathrm{As}, \mathrm{Se}, \mathrm{Br}, \mathrm{Pb}$, and $\mathrm{Zr}$. The $\mathrm{Al}_{2} \mathrm{O}_{3}$ target with a working energy of $50 \mathrm{keV}$ is ideal for $\mathrm{Cd}, \mathrm{Sb}$, and $\mathrm{Ba}$, while the Co target has an energy range of $12.5 \mathrm{keV}$ for the analysis of $\mathrm{K}, \mathrm{Ca}, \mathrm{Ti}, \mathrm{V}, \mathrm{Cr}$, and $\mathrm{Mn}$. The HOPG target's working tube voltage is $12.5 \mathrm{keV}$, which is good for $\mathrm{Na}, \mathrm{Mg}, \mathrm{Al}, \mathrm{P}, \mathrm{S}$, and $\mathrm{Cl} ; 18$ elements, i.e., $\mathrm{As}, \mathrm{Br}, \mathrm{Ca}, \mathrm{Cr}, \mathrm{Cu}, \mathrm{Fe}, \mathrm{K}, \mathrm{Mg}, \mathrm{Mn}, \mathrm{Na}, \mathrm{Ni}, \mathrm{Pb}, \mathrm{S}, \mathrm{Se}$, $\mathrm{Ti}, \mathrm{V}, \mathrm{Zn}$, and $\mathrm{Zr}$, were analyzed with the multi-channel analyzer. A standard glass sample (Spectro Corp. Germany) was used to check the signal energy and the multi-channel twice a month. The standard calibration curve between the intensity of the signal and the elemental concentrations is determined by single-element Mylar filters. Seven blank quartz filters were analyzed with the Mylar matrices method. The averaged background of blank filters was subtracted during spectral processing. The detailed procedures at LAC-CAMS can be found in previous studies (X. Y. Zhang et al., 2012).

After XRF analysis, a portion of the filter samples was extracted with $25 \mathrm{~mL}$ of double-deionized (DDI) water using a $3^{\prime \prime} \times 5^{\prime \prime}$ clean-room Poly bag (Clean Room Products, Inc., Ronkonkoma, NY). The resulting extracts were analyzed for $\mathrm{SO}_{4}^{2-}, \mathrm{NO}_{3}^{-}, \mathrm{NH}_{4}^{+}$, and other ionic species, including $\mathrm{Na}^{+}, \mathrm{K}^{+}, \mathrm{Ca}^{2+}, \mathrm{Mg}^{2+}, \mathrm{F}^{-}$, and $\mathrm{Cl}^{-}$by ion chromatography (Dionex JCS 3000) with an OmniPac Pax-500 column, $25 \mathrm{mM} \mathrm{H}_{2} \mathrm{SO}_{4}$ autoregenerant, gradient elution (from 5 to $28.75 \mathrm{mM} \mathrm{NaOH} / 5 \%$ methanol) at the Key Laboratory of Atmospheric Chemistry, CMA. The detailed protocol can be found in a previous study (Zhang et al., 2002).

The thermal/optical reflectance (TOR) carbon analysis method for element carbon (EC) and organic carbon (OC) content was performed following the Interagency Monitoring of Protected Visual Environments (IMPROVE) protocol (Chow et al., 1993, 2004). The sample filter was heated stepwise at temperatures of $120^{\circ} \mathrm{C}(\mathrm{OC} 1), 250^{\circ} \mathrm{C}(\mathrm{OC} 2)$, $450^{\circ} \mathrm{C}(\mathrm{OC} 3)$, and $550^{\circ} \mathrm{C}(\mathrm{OC} 4)$ in a non-oxidizing (He) atmosphere, and at $550^{\circ} \mathrm{C}(\mathrm{EC} 1), 700^{\circ} \mathrm{C}(\mathrm{EC} 2)$, and $800^{\circ} \mathrm{C}$ (EC3) in an oxidizing atmosphere of $2 \%$ oxygen and $98 \%$ $\mathrm{He}$; evolved carbon is oxidized to $\mathrm{CO}_{2}$ and then reduced to $\mathrm{CH}_{4}$ for detection by FID. The pyrolyzed or charred OC is monitored by reflectance at $\lambda=633 \mathrm{~nm}$. The portion of EC1 until the laser signal returns to its initial value is assigned to pyrolyzed organic carbon $(\mathrm{OP})$. The $\mathrm{OC}$ is defined by the sum of $\mathrm{OC} 1, \mathrm{OC} 2, \mathrm{OC} 3, \mathrm{OC} 4$, and $\mathrm{OP}$ while the EC is defined by $\mathrm{EC} 1+\mathrm{EC} 2+\mathrm{EC} 3-\mathrm{OP}$. The detailed procedures at LAC-CAMS can be found in previous studies (Zhang et al., 2008).

\subsection{Parameterized a index (PLAM) for evaluating specific meteorological condition that resulted in severe aerosol pollution}

In this study, we used a parameterized index, namely, PLAM, which was derived from a relationship of $\mathrm{PM}_{10}$ and key meteorological parameters from 2000 to 2007 from various region of China by our group. The PLAM index was 
used to evaluate the contribution of meteorological factors to changes in atmospheric composition and optical properties over Beijing during the 2008 Olympic Games (Zhang et al., 2009), and to identify the contribution of specific meteorological factors to the 10-day haze-fog event in 2013 (Zhang et al., 2013). Based on a set of weather sensitive parameters, an integrated index "PLAM" was parameterized (Wang et al., 2012; Yang, 2009). Among these factors, high temperature, high humidity, moderate wind, and high stability were the most relevant to the poor air quality in China. The PLAM was thus established as a function of the following parameters:

$\operatorname{PLAM}(F) \in f\left(p, t, w, \mathrm{rh}, e, s, c^{\prime}, \ldots\right)$,

where $p, t, w, \mathrm{rh}, e, s$, and $c^{\prime}$ represent air pressure, air temperature, winds, relative humidity, evaporability, stability, and effective parameter associated with the contribution of air pollution $\beta\left(c^{\prime}\right)$, respectively.

A stable summer weather with high air temperature, high relative humidity, moderate winds, and stability might create a microenvironment for high $\mathrm{PM}_{10}$ concentrations in August over Beijing (Yang, 2009), and this climate corresponds to static dynamic forcing (baroclinicity) and thermal forcing (equivalent potential temperature $\left(\theta_{\mathrm{e}}\right)$ gradient) in moist adiabatic processes in the atmosphere (Gao et al., 2004). Part of the temperature profile is between the adiabatic lapse rate (neutral stability) and the isothermal lapse rate (Johnson and Baker, 1997). Condensation is also a key factor that contributes to intense pollution at given weather conditions in the moist adiabatic processes in the atmosphere. Apparently, the final PLAM can be attributed to two major separate factors: (1) initial meteorological conditions $\alpha(m)$ associated with the atmospheric condensation processes and (2) a dynamic effective parameter associated with the initial contribution of air pollution $\beta\left(c^{\prime}\right)$, such as

$\operatorname{PLAM}=\alpha(m) \times \beta^{\prime}(c)$.

The details have been described in Wang et al. (2012) and Yang (2009).

\section{Results and discussion}

\subsection{Spatial distribution of chemical components}

The CAWNET observational network covers all areas of China with 30 ground-based stations that have been operating since 2006. Concentrations of $\mathrm{SO}_{4}^{2-}, \mathrm{OC}, \mathrm{NO}_{3}^{-}, \mathrm{NH}_{4}^{+}$, $\mathrm{EC}$, and mineral aerosols were measured in this paper by using $\mathrm{PM}_{10}$ filter samples collected from 13 stations, which are located in haze region I (Dalian), haze region II (Gucheng, Zhengzhou, and XiAn), haze region III (LinAn, Jinsha, and Change), haze region V (Panyu and Nanjing), haze region VI (Chengdu), haze region VIII (Lasha, but data in this study were just from 2006 to 2010), and haze region IX (Gaolanshan and Dunhung) (Fig. 1; X. Y. Zhang et al., 2012). Mineral aerosol was the largest component in almost all stations based on 5-year average data from 2006 to 2010 (Fig. 2a). Thus, high dust is a character in aerosol pollution in China. In general, a high mineral concentration was observed in Northwest China, thereby indicating the influence of dust from natural Asian dust sources. However, in the southern margin of the Loess Plateau in XiAn, the mineral level exceeded those in stations closer to natural dust sources (Dunhuang, Galanshan, etc.). Thus, urban fly coal ash and fugitive dust sources were also observed to affect the mineral levels in these areas. Based on the measurement results of non-crustal $\mathrm{Ca}$ in coarse particle fractions, especially during non-spring seasons (with fewer occurrences of Asian sand and dust storms - SDSs), part of the mineral dust is hypothesized to originate from construction activities and coal ash (Zhang et al., 2002). As such, even in the southern part of China where the influence of Asian dust is low, concentrations of these minerals are still significant. Mineral dust was characterized by using the surrogate concentration of $\mathrm{Fe}$, which is around $4 \%$ in the Chinese mineral dust mass. This approach has been used in our previous papers in various ambient conditions and areas in China, and has been proved to be able to estimate mineral dust content properly (Zhang et al., 1993, 2003; X. Y. Zhang et al., 2012), although the uncertainties are still present. We did not use the oxides of $\mathrm{Al}, \mathrm{Si}, \mathrm{Fe}, \mathrm{Ca}, \mathrm{Mg}$, or Ti to estimate mineral aerosol concentrations, mainly because we found (in our previous work) that we can get a similar concentration of mineral aerosols by using this simple method (just on the basis of $\mathrm{Fe}$ ) and by using oxides of various element, which will probably bring about extra uncertainties due to limitation of elemental analysis; another reason is that we cannot measure $\mathrm{Si}$ or Al with relatively higher accuracy by using Whatman quartz microfiber filters as the filtration media while simultaneously measuring water-soluble constituents, carbonaceous species, and mineral aerosol.

It is hard to separate the relative contributions of coal ash and other sources to mineral aerosol mass by only using $\mathrm{Fe}$, but the contribution of coal ash to mineral aerosols do existed in China. However, the contribution of this part from incomplete coal combustion tended to be ignored in the previous source apportionment, which deserves further attention.

The highest mean concentrations of $\mathrm{SO}_{4}^{2-}$ in aerosol particles from 2006 to 2010 were larger than $33 \mu \mathrm{g} \mathrm{m}^{-3}$ at the urban stations of XiAn, Zhengzhou in haze region II, and at Chengdu in haze region VI. This result indicates that the effect of coal combustion emissions was high in these areas (Fig. 2a). The lowest concentrations $\left(<6 \mu \mathrm{g} \mathrm{m}^{-3}\right)$ were observed in the western desert area (Dunhuang) and the Tibetan Plateau (Lasha); thus, the effect of coal combustion is low. The spatial patterns of total inorganic ammonia ions $\left(\mathrm{NH}_{4}^{+}\right)$ in China are fairly similar to those of $\mathrm{SO}_{4}^{2-}$ and $\mathrm{NO}_{3}^{-}$. Aside from XiAn, Zhengzhou, and Chengdu, stations with high 
$\mathrm{NO}_{3}^{-}$concentrations also include those further north of China (Gucheng and Dalian) with concentrations $>11 \mu \mathrm{g} \mathrm{m}^{-3}$, even at Panyu in the Pearl River Delta area of haze region V, mainly because of the influences from both motor vehicles and coal combustion as well as natural gas burning (reason discussed later).

Concentrations of OC and EC are similar to the distribution of $\mathrm{SO}_{4}^{2-}$, and the highest concentrations of $\mathrm{OC}$ (20 to $30 \mu \mathrm{g} \mathrm{m}^{-3}$ ) and EC (7 to $10 \mu \mathrm{g} \mathrm{m}^{-3}$ ) at XiAn, Zhengzhou, Gucheng, and Chengdu in haze region II and haze region VI in Southwest China and the lowest concentrations were observed in rural Northwest China and at the Tibetan Plateau. These higher levels are typically observed in regions with a high population density and are associated with emissions from biomass burning, traffic, and power generation (X. Y. Zhang et al., 2012).

\subsection{Chemical proportions of $\mathrm{PM}_{10}$ and their changes from 2006 to 2013}

From Fig. 2b, the highest concentrations of $\mathrm{PM}_{10}$ during 2013 were observed at urban stations of XiAn ( $\sim 320 \mu \mathrm{g} \mathrm{m}^{-3}$ ), followed by 200 to $240 \mu \mathrm{g} \mathrm{m}^{-3}$ at Gucheng and Zhengzhou. These stations are all located in haze region II (the Hua Bei Plain (HBP) area), which is considered as the most seriously polluted region in China in terms of aerosol pollution. This result is similar to those obtained from 2006 to 2007 (X. Y. Zhang et al., 2012). In rural Northwest China (Gaolanshan and Dunhuang station), the $\mathrm{PM}_{10}$ levels ( 240 to $250 \mu \mathrm{g} \mathrm{m}^{-3}$ ) remain high, but chemical compositions are different with higher mineral fractions. In the Yangtze River Delta area in central-eastern China (LinAn, Jinsha, and Changde) in haze region III, the $\mathrm{PM}_{10}$ levels (70 to $90 \mu \mathrm{g} \mathrm{m}^{-3}$ ) were 3 times lower than those in the HBP, but the stations in haze region III are located in rural areas and those in the HBP are in urban areas. In the Chengdu urban station located in haze region VI, which is also called the $\mathrm{Si}$ Chuan Basin (SCB) area in Southwest China, the $\mathrm{PM}_{10}$ level went up to $\sim 160 \mathrm{\mu g} \mathrm{m}^{-3}$, and this value is between the level of Gucheng $\left(200 \mathrm{\mu g} \mathrm{m}^{-3}\right)$ and Dalian in Northeast China in haze region I $\left(90 \mu \mathrm{g} \mathrm{m}^{-3}\right)$. Thus, the SCB is considered to be another polluted region in China, followed by Northeast China. The urban PM level in haze region V (Pearl River Delta (PRD) area), with values of $\sim 90 \mu \mathrm{g} \mathrm{m}^{-3}$ at Panyu and Nanning, were similar to those in rural areas in haze region III, thereby showing that the area had relatively low aerosol pollution in 2013.

During 2013, mineral dust was still the dominant fraction over various regions with a relatively high proportion, especially in rural Northwest China (Gaolanshan and Dunhuang). Mineral dust accounted for about 75 to $85 \%$ of $\mathrm{PM}_{10}$. In other areas, the percentage was between 25 and $50 \%$.

In most of areas of China except rural Northwest China, sulfate contributed the second, and the first large anthropogenic, mass fraction to atmospheric aerosol with a range of 12 to $25 \%$. In the other three stations (Gucheng, XiAn, and Panyu), the sulfate fractions were bit lower than OC and ranked third with a range of about $9-16 \%$ (Fig. 2b). As such, coal combustion was still the largest anthropogenic source of aerosol pollution in various areas of China during 2013. These sulfate proportions and related conclusions are quite similar to those from our previous study, where we mainly focused on the classification of sources of aerosol in various regions in China from 2006 to 2007 (Zhang, 2013, 2014), and from 2007 to 2008 in urban Beijing (X. Zhang et al., 2012). Table 1 shows the proportion change of each chemical component of $\mathrm{PM}_{10}$ in haze region II (Gucheng). No evident changes were observed from 2006 to 2013, again indicating that the sources of aerosol particles did not significantly change from 2006 to 2013. This result was also observed in other major haze regions in China, but that observed in Northwest China (Gaolanshan and Dunhuang) is slightly different.

In Fig. 2b, OC normally ranked third and accounted for about $7-19 \%$ in terms of mass, with high proportions in Gucheng (19\%) and Panyu (16\%) in 2013. This value is also similar to that from 2006 to 2007 (Zhang et al., 2013). In rural Northwest China, OC accounted for $\sim 8 \%$. In the urban and rural areas of China, about 55 and $60 \%$ of OC can be attributed to secondary organic carbon (SOC) formed from volatile organic carbons (VOCs), which mainly originate from chemical plants, paint and coatings, motor vehicles (including leaks during fuel), and vegetation from natural sources (X. Y. Zhang et al., 2012). The other half of OC is primary organic carbon (POC) originating from coal combustion. Based on the emission inventory of Beijing and its vicinity (BIV) (Cao et al., 2010), about $55 \%$ of POC emissions can be attributed to coal combustion, and POC from coal combustion was estimated to account for $12 \%$ of the total $\mathrm{PM}_{1}$ mass (X. Zhang et al., 2012; Zhang et al., 2013). Still from the Beijing urban area, the primary organic aerosol (POA) from coal combustion was also found to be the most important fraction of total POA, and accounted for $\sim 33 \%$ of total organic aerosol (Sun et al., 2014). Biomass burning and motor vehicles are the two other major sources for POC (Cao et al., 2010; Lu et al., 2011), and their contribution to OC will be discussed in Sect. 3.4.

The mass fractions of nitrate and ammonium normally were around 5 to $10 \%$ and 3 to $7 \%$, respectively. The mass fraction of nitrate was less than $5 \%$ in rural Northwest China (Gaolanshan and Dunhung) and that of ammonium was less than $3 \%$ in rural Northwest China, urban haze region $\mathrm{V}(\mathrm{Pa}-$ nyu), and urban haze region I (Dalian) (Figure 2b). The percentage of nitrate and ammonium in 2013 had no significant differences from those in 2006 and 2007 (Zhang et al., 2013). Comparing the nitrate mass in $\mathrm{PM}_{10}$ among the stations within haze region II in 2013 (Table 2), concentrations in urban Beijing $\left(\sim 20 \mu \mathrm{g} \mathrm{m}^{-3}\right.$; from 2009 data because no data were obtained in 2013) were not higher than those in other stations (19 to $22 \mu \mathrm{g} \mathrm{m}^{-3}$ for Zhengzhou, Gucheng, 

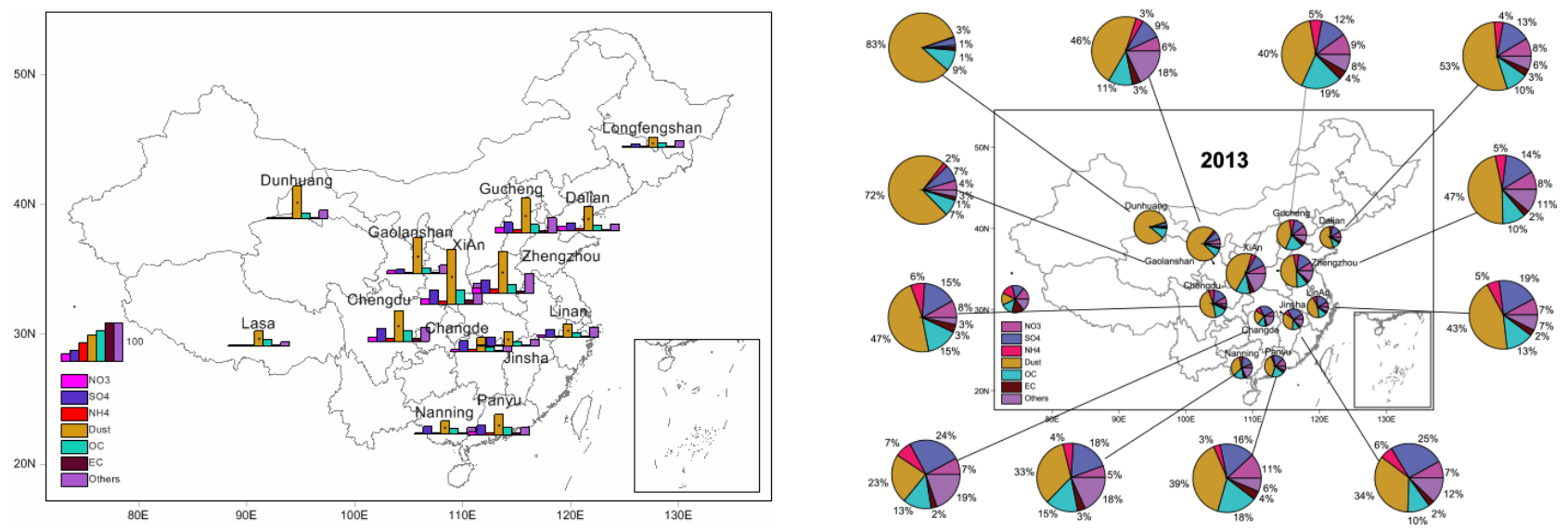

Figure 2. (a) Averaged mass concentrations $\left(\mu \mathrm{g} \mathrm{m}^{-3}\right.$ ) of major chemical components in 13 stations during 2006-2010. (b) Chemical proportions of $\mathrm{PM}_{10}$ in 2013 .

Table 1. Proportion change in major chemical components of $\mathrm{PM}_{10}$ at Gucheng.

\begin{tabular}{lcccccccc}
\hline & 2006 & 2007 & 2008 & 2009 & 2010 & 2011 & 2012 & 2013 \\
\hline $\mathrm{NO}_{3}^{-}$ & 0.10 & 0.07 & 0.04 & 0.07 & 0.06 & 0.06 & 0.09 & 0.10 \\
$\mathrm{SO}_{4}^{2-}$ & 0.16 & 0.14 & 0.09 & 0.12 & 0.13 & 0.13 & 0.10 & 0.12 \\
$\mathrm{NH}_{4}^{+}$ & 0.07 & 0.05 & 0.04 & 0.04 & 0.04 & 0.04 & 0.05 & 0.06 \\
$\mathrm{Mineral}$ & 0.32 & 0.36 & 0.42 & 0.48 & 0.52 & 0.32 & 0.44 & 0.40 \\
$\mathrm{OC}$ & 0.14 & 0.14 & 0.11 & 0.13 & 0.16 & 0.16 & 0.17 & 0.19 \\
$\mathrm{EC}$ & 0.05 & 0.04 & 0.03 & 0.04 & 0.04 & 0.04 & 0.04 & 0.04 \\
Others & 0.17 & 0.23 & 0.28 & 0.13 & 0.05 & 0.25 & 0.12 & 0.08 \\
\hline
\end{tabular}

and XiAn). However, the contribution from motor vehicle emissions is the largest in BIV (NBS-Beijing, 2013). This result shows that nitrate over the region originates not only from motor vehicle emissions but also from coal combustion. Even in BIV, about $28 \%$ of the amount of $\mathrm{NO}_{x}$ emissions can still be attributed to coal combustion. In other areas in China, about $50 \%$ of nitrate mass can be attributed to coal combustion (Cao et al., 2010). Globally, $\mathrm{NO}_{x}$ is mainly derived from natural sources. However, in urban areas, $\mathrm{NO}_{x}$ mainly comes from anthropogenic activities such as oil and coal combustion. Given the rapid development of China's economy in recent years, the amount of gasoline and diesel oil consumption has significantly increased over the past few years $(\mathrm{Lu}$ et al., 2011), even though the Chinese government started promoting the "low nitrogen combustion technology" for denaturalization in power generation in 2012. The installation capacity reached only around $70 \%$ by mid-2013, except in BIV (meeting communication), which can probably explain the high nitrate concentrations in HBP.

In most areas in China (Fig. 2b), EC normally accounts for 3 to $4 \%$ of aerosol mass, with less than $2 \%$ in rural Northwest China (Fig. 2b); this result is also similar to the data obtained from 2006 to 2007 (Zhang et al., 2013). The EC has similar sources with POC (Cao et al., 2010), and is not a major chemical fraction in aerosol particles over China.
Almost similar concentrations were found for each chemical component in aerosol particles with diameters less than $10 \mu \mathrm{m}\left(\mathrm{PM}_{10}\right)$, and less than $2.5 \mu \mathrm{m}\left(\mathrm{PM}_{2.5}\right)$ were observed in urban Beijing (Table 2). These results provide further evidence that the secondary aerosol particle (sulfate, nitrate, ammonium, and SOC) and particles from combustion processes (EC and POC) are present in particles with a diameter of $<2.5 \mu \mathrm{m}$.

\subsection{Changes in annual mean concentrations of chemical components}

Table 2 provides the annual averaged daily concentrations for $\mathrm{PM}_{10}$ of major chemical components in six major haze areas of China from 2012 to 2013. In the Gucheng station (haze region II), the annual mean concentrations of most chemical components had no significant difference between 2013 and 2012, except OC with an increase of $\sim 10 \mu \mathrm{g} \mathrm{m}^{-3}$ in 2013. This result indicates that no significant difference was observed in emission between the two years. About 37.5 and 36.2 billion tons of standard coal were used for energy consumption in 2013 and 2012 (NBS-China, 2014), respectively, and the difference is not that large. The mass of mineral aerosol in 2013 was even bit lower than that in 2012, resulting in a relatively lower yearly mean $\mathrm{PM}_{10}$ concentration 
Table 2. Annual averaged daily concentrations $\left(\mu \mathrm{g} \mathrm{m}^{-3}\right)$ for $\mathrm{PM}_{10}$, chemical components in various regions of China during 2013 and 2012.

\begin{tabular}{|c|c|c|c|c|c|c|c|c|c|c|}
\hline Stations & Type & Region & $\mathrm{PM}_{10}$ & Mineral & $\mathrm{SO}_{4}^{2-}$ & OC & $\mathrm{NO}_{3}^{-}$ & $\mathrm{NH}_{4}^{+}$ & $\mathrm{EC}$ & No. \\
\hline \multicolumn{11}{|l|}{ Haze region II (HBP) $)^{\mathrm{a}}$} \\
\hline Gucheng (GC)-2013 & semi-urban & Province south of Beijing & 196 & 74 & 21 & 45 & 17 & 10 & 10 & 52 \\
\hline 2012-GC & & & 203 & 84 & 20 & 36 & 17 & 10 & 8.1 & 101 \\
\hline Zhengzhou (ZZ)-2013 & urban & Province south of Beijing & 235 & 110 & 35 & 26 & 20 & 13 & 6.6 & 103 \\
\hline 2012-ZZ & & & 221 & 107 & 34 & 24 & 21 & 13 & 7.0 & 105 \\
\hline XiAn (XA)-2013 & urban & Guanzhong Plain & 293 & 138 & 31 & 34 & 20 & 11 & 11 & 81 \\
\hline $2011-X A^{b}$ & & & 268 & 123 & 28 & 26 & 16 & 6.2 & 9.9 & 74 \\
\hline Beijing (BJ)-2009-PM $\mathrm{PM}_{10}^{\mathrm{c}}$ & urban & Haidian District of Beijing & 174 & nd & 19 & 19 & 20 & 7.6 & 4.8 & 155 \\
\hline $2009-\mathrm{PM}_{2.5}{ }^{\mathrm{c}}$ & & & 126 & nd & 17 & 16 & 16 & 8.0 & 4.1 & 153 \\
\hline \multicolumn{11}{|l|}{ Haze region III (YRD) } \\
\hline LinAn (LA)-2013 & rural & Yangtze River Delta regions & 88 & 38 & 16 & 12 & 7.3 & 5.0 & 2.5 & 100 \\
\hline 2012-LA & & & 94 & 32 & 16 & 11 & 8.4 & 5.4 & 3.3 & 102 \\
\hline Jinsha (JS) -2013 & rural & Lower reach of Yangtze River & 78 & 28 & 19 & 8.5 & 5.8 & 5.4 & 2.2 & 52 \\
\hline 2012-JS & & & 86 & 33 & 21 & 8.7 & 6.5 & 5.7 & 2.2 & 52 \\
\hline Changde (TYS)- 2013 & rural & Dongting and Buoyan lakes basin & 72 & 16 & 18 & 10 & 6.1 & 6.1 & 2.0 & 82 \\
\hline 2012-TYS & & & 87 & 16 & 21 & 11 & 7.0 & 7.1 & 1.9 & 86 \\
\hline \multicolumn{11}{|l|}{ Haze region V (PRD) } \\
\hline Panyu (PY) -2013 & urban & Pearl River Delta region & 97 & 40 & 16 & 18 & 11 & 4.2 & 3.9 & 37 \\
\hline 2012-PY & & & 97 & 39 & 16 & 14 & 10 & 4.9 & 4.0 & 33 \\
\hline Nanning (NJ) -2013 & urban & Pearl River Delta region & 90 & 30 & 17 & 14 & 5.2 & 4.6 & 3.4 & 103 \\
\hline $2010-\mathrm{NJ}^{\mathrm{b}}$ & & & 91 & 44 & 18 & 14 & 4.3 & 4.1 & 3.3 & 111 \\
\hline \multicolumn{11}{|l|}{ Haze region VI (SCB) } \\
\hline Chengdu (CD) -2013 & urban & Si Chuan Basin & 166 & 79 & 24 & 25 & 14 & 11 & 6.6 & 94 \\
\hline 2012-CD & & & 141 & 64 & 23 & 21 & 12 & 9.0 & 5.7 & 100 \\
\hline \multicolumn{11}{|l|}{ Haze region I (NE China) } \\
\hline Dalian (DL) -2013 & urban & Southern tip of Liaodong peninsula & 101 & 58 & 13 & 11 & 8.5 & 4.0 & 3.2 & 69 \\
\hline 2012-DL & & & 89 & 52 & 14 & 10 & 8.8 & 4.2 & 2.8 & 89 \\
\hline \multicolumn{11}{|l|}{ Haze region IX (NW China) } \\
\hline Gaolanshan (GLS) -2013 & rural & Gansu province & 247 & 184 & 16 & 17 & 8.9 & 4.0 & 3.2 & 103 \\
\hline 2012-GLS & & & 157 & 102 & 15 & 15 & 7.3 & 3.9 & 2.4 & 99 \\
\hline Dunhuang (DH) -2013 & rural & North margin of Kumutage Desert & 240 & 201 & 9.1 & 24 & 2.5 & 0.65 & 2.5 & 68 \\
\hline 2012-DH & & & 198 & 162 & 6.6 & 20 & 2.5 & 0.81 & 2.3 & 70 \\
\hline
\end{tabular}

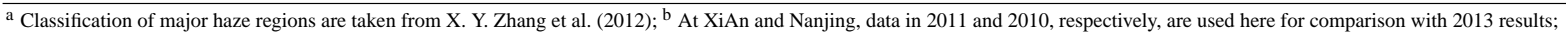

${ }^{c}$ Beijing is 2009 data for $\mathrm{PM}_{10}$ and $\mathrm{PM}_{2.5}$; Lasha data are omitted because of a lack of data from 2012 to 2013 for this station.

in 2013, but was unexpectedly associated with the occurrence of persistent heavy haze-fog events in the winter of 2013. This event did not occur in 2012. As such, this difference was the subject of studies because no significant changes were observed in the emission. Gucheng station is located in a rapidly urbanized area of Baoding city, Hebei province, which is the closest city to Beijing (about $140 \mathrm{~km}$ southwest). Zhengzhou, XiAn, and Beijing are all within haze region II. The annual concentration levels of chemical components were not significantly different between 2013 and 2012 .

A similar situation was also observed in stations such as LinAn, Jinsha, and Changde in haze region III (Yangtze River Delta (YRD) area), Panyu in haze region V (PRD area), Chengdu in haze region VI (SCB area), Dalian in haze region I (NE China), and Gaolanshan and Dunhuang in haze region IX (NW China) (Table 2). As such, no evident annual concentration differences were observed in 2012 and 2013 in terms of the major chemical components, especially those as- sociated with fine particles such as $\mathrm{SO}_{4}^{2-}, \mathrm{OC}, \mathrm{NO}_{3}^{-}, \mathrm{NH}_{4}^{+}$, and EC.

Comparing the annual averaged concentrations, the annual mean of most chemical components in 2013 are even lower than those from 2006 to 2007 (X. Y. Zhang et al., 2012). A survey of the main aerosol chemical components shows a wide spatial variability and higher concentrations for all aerosol components in aerosol mass concentrations in the same stations from both 2006 and 2007. For these annual mean concentrations, large decreases were observed in 2013 relative to the values from 2006 to 2007 in Gucheng station for various major chemical species, especially for $\mathrm{SO}_{4}^{2-}$, $\mathrm{NH}_{4}^{+}$, and $\mathrm{NO}_{3}^{-}$with 2006 to 2007 to 2013 ratios of $1.5,1.5$, and 1.2 , respectively. The only component whose concentration increased in 2013 was OC. The reason will be discussed in the next section. For EC and mineral aerosols, their concentrations exhibited no evident changes. The same result was observed for stations (Zhengzhou, XiAn) within the 
same haze region (II), where concentrations of most chemical components, except for OC and mineral aerosol, were all lower in 2013 relative to those from 2006 to 2007. Moreover, the final $\mathrm{PM}_{10}$ concentration in 2013 was also lower than that from 2006 to 2007.

\subsection{Occurrence of haze-fog event in January of 2013 as opposed to 2012 in Gucheng in haze region II as an example}

\subsubsection{Winter concentrations and year-long aerosol pollution}

The typical seasonal patterns in various aerosol components in China are summarized by X. Y. Zhang et al. (2012), where the maximum concentrations of most aerosol chemical components were observed in winter, whereas those of mineral aerosol were observed in spring. In addition to the regular seasonal maximum, secondary peaks were found for sulfate and ammonium during the summer and for OC and EC during May and June. The general changing patterns of various chemical components were also true in Gucheng at this study (Fig. 3, left panel). The OC concentrations from late autumn to winter were normally 2 to 4 times higher than those in summer, and concentrations during winter continuously declined from 2006 to 2009 and then increased from 2010 to 2013. This result can also be seen in the linear trend of wintertime concentrations from 2010 to 2013 in Fig. 3. The averaged OC concentrations in January of 2013 even reached $\sim 145 \mu \mathrm{g} \mathrm{m}^{-3}$, which is $\sim 2.2$ times higher than that in 2010 . A similar situation was also observed for $\mathrm{EC}, \mathrm{SO}_{4}^{2-}, \mathrm{NO}_{3}^{-}$, $\mathrm{NH}_{4}^{+}$, and $\mathrm{PM}_{10}$.

Although the annual mean concentration had no evident changes, the winter concentration of $\mathrm{PM}_{10}$ was higher by at least $25 \%$ in 2013 than in the winter of 2012, whereas the winter concentrations of $\mathrm{SO}_{4}^{2-}$ and $\mathrm{NH}_{4}^{+}$in 2013 even increased by a factor of 1 or near 1 relative to that in to 2012, and the OC concentration increased by $\sim 50 \%$. All these increases resulted in the heavy and persistent haze-fog event in January of 2013.

Based on the OC concentration histogram in Fig. 3 (right panel), the OC concentration is usually $15 \mu \mathrm{g} \mathrm{m}^{-3}$, which can be considered as the regularly observed background concentrations in haze region II. A peak concentration of $55 \mu \mathrm{g} \mathrm{m}^{-3}$ can be considered as the maximum wintertime mass of OC. As discussed in Sect. 3.2, the increased value of OC concentrations during the winter can be partially attributed to scattered and central centralized coal combustion during the heating season. Aside from this, the increased OC concentration during the winter was also highly correlated with biomass fuel burning in Gucheng, Baoding city, Hebei province in the south of Beijing during the winter. This is mainly inferred from the $\mathrm{OC} / \mathrm{EC}$ ratio speculation, although the uncertainties do existed. The $\mathrm{OC} / \mathrm{EC}$ ratio was 4.6 for Gucheng in the winter of 2013 and ranged from 4.1 to 4.5 during wintertime in other years. This group "Gucheng" ratio (4.1 to 4.6) is between the ratio of biomass fuel combustion (3.3) and open biomass burning (8.9 in winter, 8.0 in spring, 5.6 in summer, and 5.9 in autumn) based on the emission inventory (Cao et al., 2006, 2010), but is much higher than the ratio of coal combustion (2.0), gasoline (1.4), and diesel oil (3.0), as well as the normal value of 3.1 to 3.9 for ambient aerosol in urban areas in China (Zhang et al., 2008a). Thus, biomass fuel burning was identified to be another main source for the increase in $\mathrm{OC}$ concentrations during winter in these areas in the past few years. Baoding (Gucheng station located) is the nearest city in Hebei province to Beijing and has a population of about 11 million, in which $\sim 80 \%$ are rural dwellers living in more than 600 villages in 27 various counties. Even in urban areas with more than 2 million inhabitants, the proportion of central heating during winter in Baoding is less than $40 \%$. In the villages and counties, large amounts of biomass and scattered coal were burned during winter for heating. During summer, the OC/EC ratios ranged from 1.6 to 3.0 from 2008 to 2012 and 2.6 to 3.4 from 2006 to 2007 (Zhang et al., 2008). As such, the contribution of gasoline and diesel combustion during summer to the OC concentrations is high, which is evidently different during the winter.

The change in EC is similar to that in OC, and its background concentration is around $5 \mu \mathrm{g} \mathrm{m}^{-3}$. In winter of 2012, the value is about $21 \mu \mathrm{g} \mathrm{m}^{-3}$.

In Fig. 2b, sulfate, similar to OC, accounted for a large fraction $(\sim 12 \%)$ of $\mathrm{PM}_{10}$ in 2013 in Gucheng, and its seasonal variation pattern is similar to the general trend in other areas of China (X. Y. Zhang et al., 2012) with the maximum concentrations found during winter, and secondary peaks during summer (Fig. 3, left panel). The histogram analysis for sulfate (Fig. 3, right panel) also shows two peak values of 43 and $33 \mu \mathrm{g} \mathrm{m}^{-3}$, which may represent the peak concentrations in winter and summer, respectively. Another peak at $21 \mu \mathrm{g} \mathrm{m}^{-3}$ may represent the background value. Based on the winter sulfate concentrations from 2010 to 2013, a slight increase in $\mathrm{SO}_{4}^{2-}$ concentrations was observed from linear fitting of $\mathrm{SO}_{4}^{2-}$ in Fig. 3 (lift panel), particularly in January of 2013. A peak at $56 \mu \mathrm{g} \mathrm{m}^{-3}$ was observed, thereby indicating that the sulfate probably originated from scattered coal combustion and central heating involving the use of coal in Gucheng because the major emission sources for $\mathrm{SO}_{2}$, i.e., coal power plant and industrial manufacturing processes, would be no extra increase during winter. In China, half of coal is used for power generation. About three-quarters of another half are used in industrial manufacturing processes, mainly in steel mills, chemical plants, and glass and cement plants, and a quarter of this half can be attributed to scattered coal combustion for winter heating (Cao et al., 2010); only this part caused the increase during winter. The emissions of scattered coal combustion were those from smaller heating boilers (less than 40 tons) and those of coal burn- 

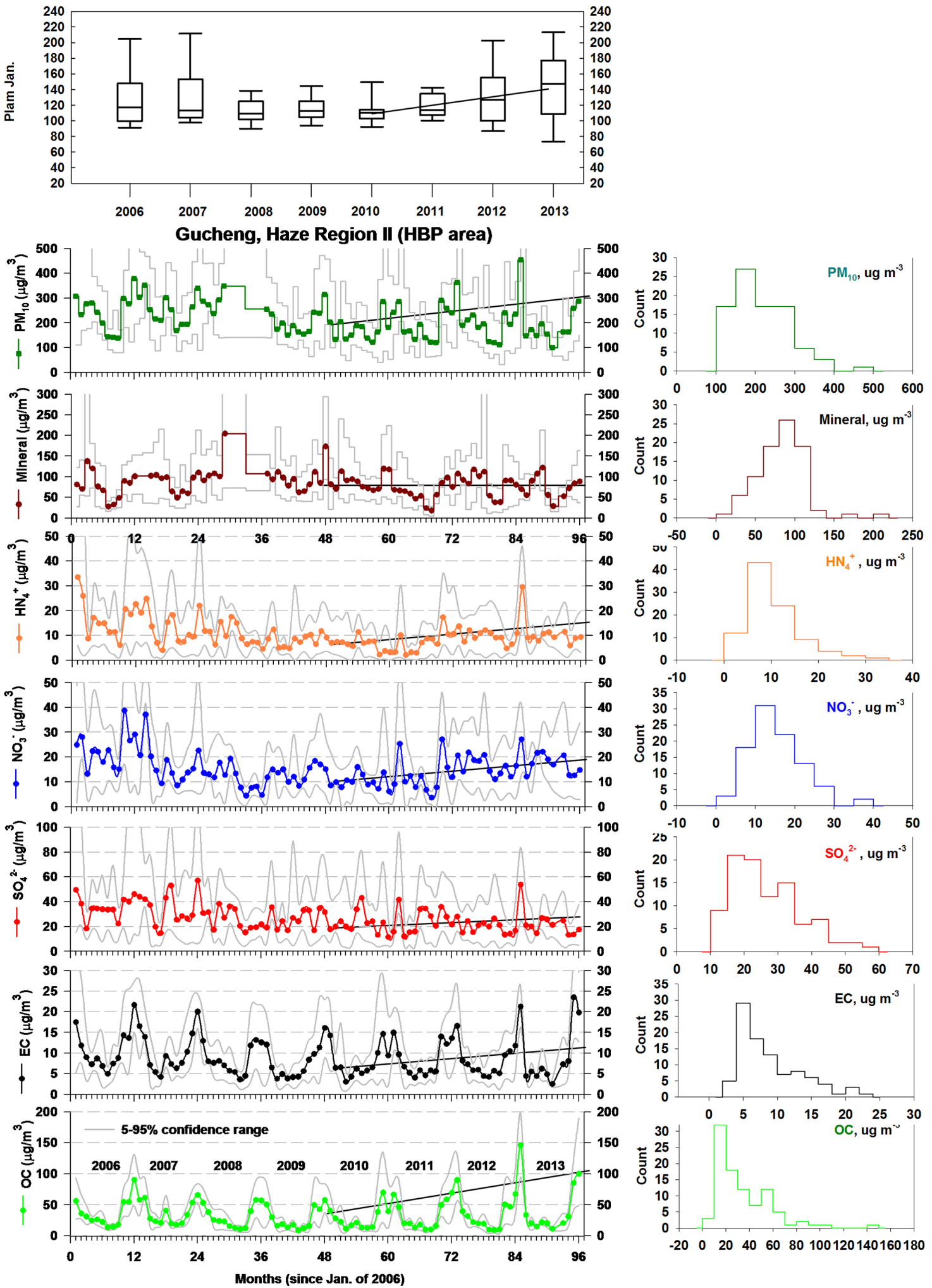

Figure 3. Left panel: change of monthly median concentrations of major chemical components, PM 10 , and January PLAM at Gucheng in haze region II, one of the major haze region in the Hua Bei Plain (HPB) area in China. Wintertime data were used in linear trend fitting from 2010 to 2013; right panel: histogram analysis for various chemical components. 
ing were from scattered residential households. All sulfate data fitting (not just based on wintertime data) still shows the decreasing trend from 2010 to 2013 ( -0.07 slope for linear fitting, data omitted), Thus, desulfurization processes in power plants, which have been carried out since 2000 in China, might cause these decreases.

Similar to sulfate, nitrate concentrations were also higher in winter relative to other seasons, and an increasing trend during winter was observed from 2010 to 2013 with less significant seasonal variations relative to OC and EC (Fig. 3, left panel). Given that the main sources of $\mathrm{NO}_{x}$ emission, i.e., coal combustion from coal power plants, industrial manufacturing processes, fuel burning from motor vehicles, and natural gas burning (Göke et al., 2014), are relatively the same for all four seasons, the contribution of scattered coal heating or central heating boilers without denitrification devices to the increase of $\mathrm{NO}_{3}^{-}$concentrations during winter cannot be ignored. The lower height of the planetary boundary layer during the winter is another reason for the high concentrations during winter. If one just compares the winter data, the effect would be eliminated. This is, of course, an important aspect to determine the impact of meteorological factors on pollution and will be discussed in the next section by using PLAM. Based on the $\mathrm{NO}_{3}^{-}$histogram result (Fig. 3, right panel), the regional background and winter peak concentrations are around 12 and $28 \mu \mathrm{g} \mathrm{m}^{-3}$, respectively. Unlike in sulfate, by using all nitrate data the linear fit still showed an increasing trend for $\mathrm{NO}_{3}^{-}$(Fig. 3, left panel), thereby showing that the denitrification in power plants has had no obvious effect on the increase in $\mathrm{NO}_{3}^{-}$concentrations since 2012.

Of the anions, $\mathrm{SO}_{4}^{2-}$ and $\mathrm{NO}_{3}^{-}$are dominant species contributing to aerosol acidities, both of which are highly correlated with $\mathrm{NH}_{4}^{+}$in Gucheng (X. Y. Zhang et al., 2012). The median ratio of the observed mole number of $\mathrm{NH}_{4}^{+}$and capable molecules for neutralizing this substance from $\mathrm{SO}_{4}^{2-}$ and $\mathrm{NO}_{3}^{-}$was approximately 0.70 from 2006 to 2013, thereby suggesting that excess overbalanced anion can sufficiently neutralize $\mathrm{NH}_{4}^{+}$in haze region II. The change in $\mathrm{NH}_{4}^{+}$concentrations since 2010 has been similar to that of $\mathrm{NO}_{3}^{-}$, with the same tendency to increase during winter (Figure 3, left panel). The frequency distribution was also similar to that of $\mathrm{NO}_{3}^{-}$but different to that of $\mathrm{SO}_{4}^{2-}$ (Fig. 3, right panel). The frequency distribution analyses of $\mathrm{NH}_{4}^{+}$concentrations also showed that the background and winter concentrations were 7.5 and $23 \mu \mathrm{g} \mathrm{m}^{-3}$, respectively (Fig. 3, right panel). Both values are much higher in the HBP area than in other regions, which imply that the major sources of $\mathrm{NH}_{4}^{+}$are located in the HBP. Waste and coal consumption account for $\sim 67$ to $85 \%$ of the total $\mathrm{NH}_{3}$ emissions, of which human and poultry wastes as well as coal combustion from industry, commercial, and residential usage are the major contributors in urban areas (Cao et al., 2010). In rural areas, another source of ammonia emissions is agricultural activities, which account for $\sim 14$ to $28 \%$ of the total $\mathrm{NH}_{3}$ emission, with nitrogen fertilizer as the major contributor (Cao et al., 2010).

In Fig. 3, left panel, the linear trend of winter mineral aerosol concentrations shows almost no change from 2010 to 2013 , thereby indicating that the change in $\mathrm{PM}_{10}$ in these years was mainly attributed to the changes in fine aerosol particle concentrations. The histogram analysis of the mineral suggests that a high regional background loading of $90 \mu \mathrm{g} \mathrm{m}^{-3}$ was observed in haze region II, which is caused by not only sand-dust-storm dust and urban fugitive dust, but also coal ash that is closely related to the large amount of coal combustion activity in this area. The winter concentrations of mineral aerosol are around $130 \mu \mathrm{g} \mathrm{m}^{-3}$ (Fig. 2, right panel).

\subsubsection{Contribution of specific meteorological condition to the wintertime $\mathbf{P M}_{10}$ changes}

The $\mathrm{PM}_{10}$ concentrations increased by about $25 \%$ in January of 2013 compared with that in 2012. The specific meteorological conditions that are highly related to aerosol pollution (parameterized as an index called "PLAM") also increased by $\sim 15 \%$ at the same period. Given that the pollutant emissions did not significantly change from 2012 to 2013 (NBS-China, 2014), which was not enough to cause a significant increase of 25 , about $60 \%$ of this $25 \%$ increase in $\mathrm{PM}_{10}$ concentrations can thus be considered as the contribution of worsening meteorological conditions, because PLAM has been confirmed to be linearly related to $\mathrm{PM}_{10}$ concentrations (Wang et al., 2012).

The comparison of averaged $\mathrm{PM}_{10}$ concentrations between January 2013 and January 2010 also showed that the mean value in 2013 was 1.2 times higher than that in 2010, whereas the PLAM index increased to about $35 \%$ in 2013 compared with that in 2010. Given the linear relation between PLAM and $\mathrm{PM}_{10}$ (Wang et al., 2012), about $28 \%$ of the 1.2 times increase in $\mathrm{PM}_{10}$ can be approximately regarded as the contribution from worsening meteorological conditions since 2010. Based on the changes in mean mass of various chemical components between January 2010 and January 2013 and by multiplying these by the proportion of each component of $\mathrm{PM}_{10}$ in 2013 (Fig. 2b), about 20, 41, 18, $16,2.0$, and $-5.0 \%$ of the increase in $\mathrm{PM}_{10}$ in 2013 relative to 2010 can be attributed to $\mathrm{SO}_{4}^{2-}, \mathrm{OC}, \mathrm{NO}_{3}^{-}, \mathrm{NH}_{4}^{+}, \mathrm{EC}$, and mineral, respectively. The other components accounted for about $\sim 9 \%$ of this increase in $\mathrm{PM}_{10}$ concentrations between 2010 and 2013. OC contributed the largest percent of the increase in $\mathrm{PM}_{10}$ concentrations from 2010 to 2013. 


\subsection{Changes in the chemical components of $\mathrm{PM}_{10}$ in other major haze areas in China}

\subsubsection{Haze region III (Yangtze River Delta area) in China}

Although the winter concentrations of particular aerosol chemical components, such as $\mathrm{OC}, \mathrm{NO}_{3}^{-}$, and $\mathrm{NH}_{4}^{+}$, have continuously increased since 2010 in haze region III (LinAn) (Fig. 4, left panel), the increase in amplitude has been much smaller than that of HBP. The winter concentrations of EC and dust slightly decreased and that of sulfate did not significantly change from 2010 to 2013 . Thus, $\mathrm{PM}_{10}$ concentrations have remained unchanged since 2010, which has been very similar to the change in wintertime PLAM in the same area. This result implies the important effect of meteorological conditions on aerosol pollution. In general, the pollution-meteorological condition worsened from 2006 to 2010 in haze region III (LinAn) and remained almost unchanged from 2010 to 2013 with a slight decrease in 2011 (Fig. 4, left panel: upper part).

The regional background concentrations of $\mathrm{SO}_{4}^{2-}, \mathrm{OC}$, $\mathrm{NO}_{3}^{-}, \mathrm{NH}_{4}^{+}, \mathrm{EC}$, and mineral dust are normally $17,11,6,6$, 3 , and $25 \mu \mathrm{g} \mathrm{m}^{-3}$, respectively, which are about 60 to $80 \%$ of the HPB level (Fig. 4, right panel). The corresponding winter values are normally $33,22,15,10,5$, and $65 \mu \mathrm{g} \mathrm{m}^{-3}$, respectively. The winter values were still double or twice as high as the annual background concentrations, but concentrations are much smaller than in HBP, thereby suggesting the weak influence of winter heating in the YRD area. Winter heating is not legally imposed in the southern parts of China. However, coal-fired heating during winter is still practiced in this area, which can increase the mineral content to $65 \mu \mathrm{g} \mathrm{m}^{-3}$ during winter from the normal value of $25 \mu \mathrm{g} \mathrm{m}^{-3}$. The increased wintertime mineral concentrations are most likely caused by coal ash, whereas other fugitive dust, such as dust from sand and dust storm events, construction sites, and unpaved roads, would cause a significant increase during winter. Unlike in HBP, the proportion of sulfate $\left(\sim 19 \%\right.$ of $\left.\mathrm{PM}_{10}\right)$ is much higher than the OC fraction ( $13 \%$ of $\left.\mathrm{PM}_{10}\right)$.

The winter OC/EC ratio was 3.7 with a range of 2.7 to 5.3 from 2006 to 2013 in haze region III (LinAn), and a high value of $\sim 4.0$ was observed from 2012 to 2013 . These values are similar to those from biomass fuel combustion (Cao et al., 2010), thereby suggesting that the influence of biomass burning for heating was also observed in the YRD area during winter.

\subsubsection{Haze region $\mathbf{V}$ (Pearl River Delta area) in China}

The pollution-meteorological conditions during wintertime were much better in haze region V (Panyu) in the PRD area than that in the HBP, with PLAM values ranging from 60 to 90 from 2010 to 2013 (corresponding values of 110 to 150 in HPB; $\sim 120$ to 125 in the YRD) and are associated with a declining trend (Fig. 5, left panel: upper part). This decrease in PLAM was very similar to the decreased trend of $\mathrm{PM}_{10}$, thereby implying the effect of meteorological factors on the change in PM. In Fig. 5, almost all chemical components have presented a decrease since 2010, except for nitrate. In addition to the reduced emission in the YRD with emphasis on coal combustion sources, the decrease in concentrations of major chemical components and $\mathrm{PM}_{10}$ can also be partially attributed to improved meteorological conditions that have occurred since 2010. The proportion of coal in primary energy consumption decreased to $49 \%$ in 2013 in Guangzhou. The corresponding number is $60 \%$ in 2004 (meeting communication).

The regional background concentrations of $\mathrm{SO}_{4}^{2-}, \mathrm{OC}$, $\mathrm{NO}_{3}^{-}, \mathrm{NH}_{4}^{+}, \mathrm{EC}$, and mineral dust in this region are 17, 13, 9, $7,3.5$, and $25 \mu \mathrm{g} \mathrm{m}^{-3}$, respectively, which are similar to the values in the YRD. The corresponding winter values are 33, $22,15,9,6.7$, and $70 \mu \mathrm{g} \mathrm{m}^{-3}$ for $\mathrm{SO}_{4}^{2-}, \mathrm{OC}, \mathrm{NO}_{3}^{-}, \mathrm{NH}_{4}^{+}, \mathrm{EC}$, and mineral, respectively. The difference between the winter and background concentrations in other seasons in the PRD area is very similar to those in the YRD area.

The winter OC / $\mathrm{EC}$ ratio in haze region $\mathrm{V}$ (Panyu) is 0.79 with a range of 0.25 to 2.9 from 2006 to 2013, which is close to the value of 1.4 for gasoline (Cao et al., 2010). Thus, different sources were noted in the HBP area for OC and EC with less biomass burning contributions. In January of 2006, 2008, and 2009, the OC/EC ratios were within the range of 2.4 to 2.9 , which was very similar to fossil fuel combustion (2.0) and diesel oil (3.0) (Cao et al., 2010). As such, emission had an evident effect in reducing the contribution of coal combustion and diesel vehicles in Guangzhou. After 2010 , the winter ratio of $\mathrm{OC}$ and $\mathrm{EC}$ were within 0.3 to 0.5 .

\subsubsection{Haze region VI (Si Chuan Basin area) in China}

Based on the monthly changes in the various chemical components and $\mathrm{PM}_{10}$ in haze region VI (Chengdu) (Fig. 5, left panel), the wintertime mass of various chemical components generally had peak values from 2006 to 2013 . However, in particular years, this kind of situation was not particularly evident. These results suggest that the wintertime heating season had an effect on the chemical composition in the SCB area. Specifically, the mass of mineral aerosol was found to have an evident peak in winter, which is different from other areas. As such, the influences of coal-ash contribution were observed. The significant increase in concentrations during winter was not evident for sulfate relative to other chemical species, such as EC and nitrate, especially after 2010, because another period had existed in the summer where the values were at their maximum. Moreover, the decreasing trend of sulfate in January from 2010 to 2013 shows the effect of desulfurization in this area. The opposite behavior was observed for nitrate during the same period, showing no obvious denitrification effect of power generation plants. During winter, PLAM decreased from 2006 to 2009 and remained 

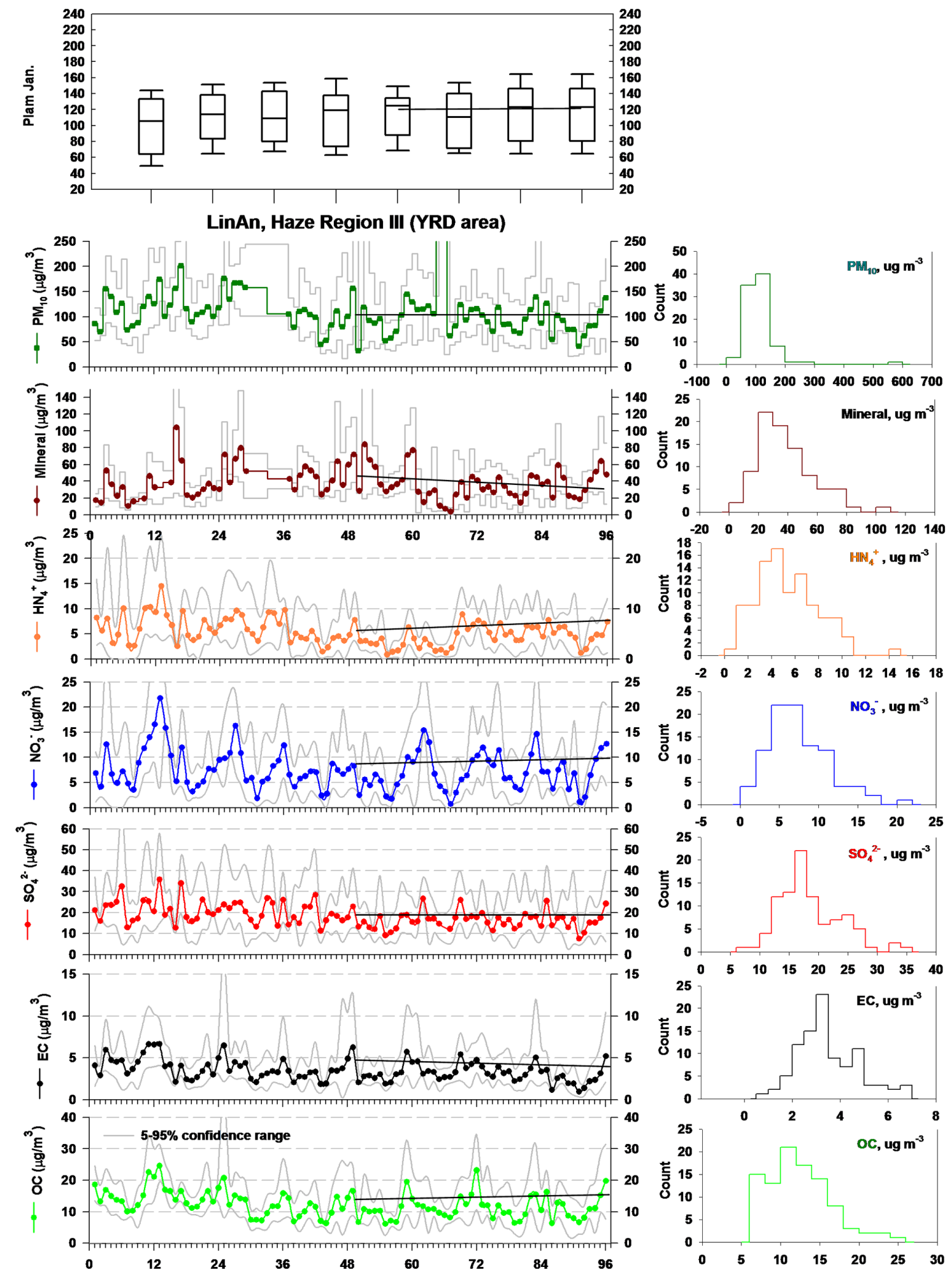

Figure 4. Left panel: change of monthly median concentrations of major chemical components, PM 10 , and January PLAM at LinAn in haze region III, one of the major haze region in the Yangtze River Delta (YRD) area in China. Wintertime data were used in linear trend fitting from 2010 to 2013; right panel: histogram analysis result for various chemical components. 


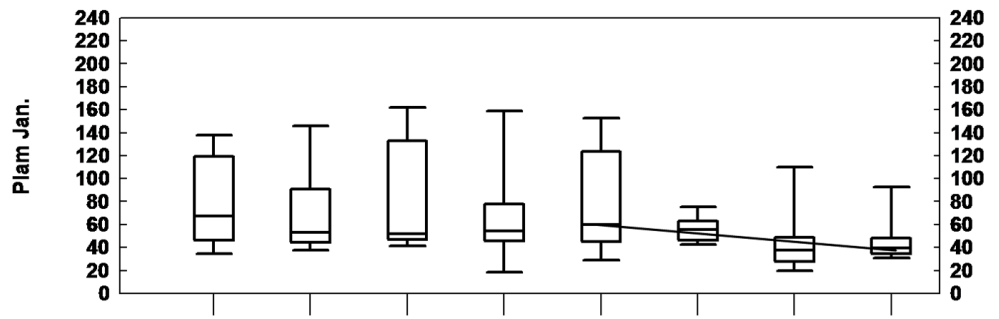

Panyu, Haze Region V (PRD area)
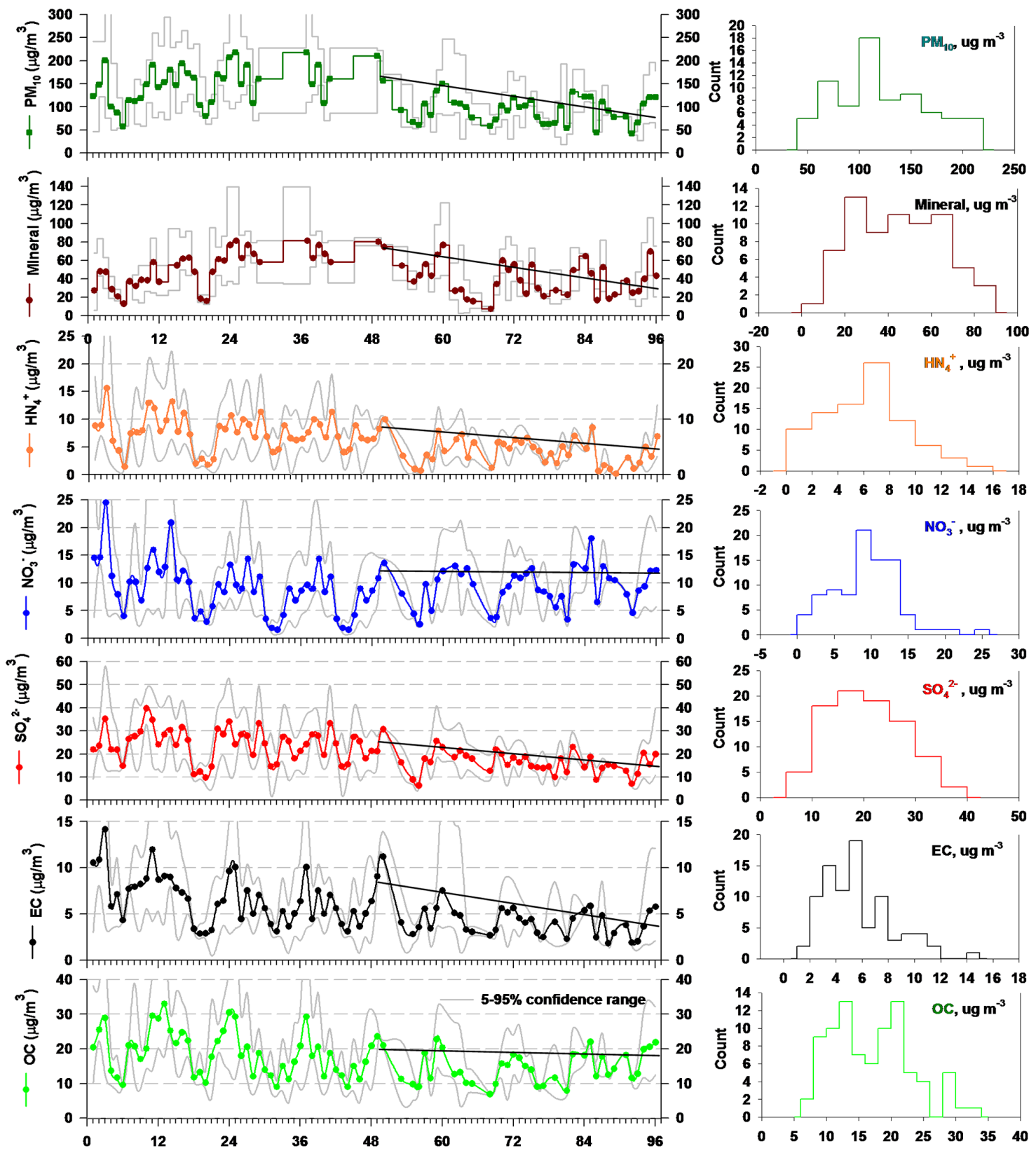

Figure 5. Left panel: change of monthly median concentrations of major chemical components, PM 10 , and January PLAM at Panyu in haze region V, one of the major haze region in the Pearl River Delta (PRD) area in China. Wintertime data were used in linear trend fitting from 2010 to 2013; right panel: histogram analysis result for various chemical components. 
at a similar level of $\sim 130$ from 2010 to 2013 . However, the value was low in 2011, thereby showing that the effect of bad weather on aerosol pollution is medium in the SCB area (Fig. 5, left panel: upper part).

The background concentrations of $\mathrm{SO}_{4}^{2-}, \mathrm{OC}, \mathrm{NO}_{3}^{-}, \mathrm{NH}_{4}^{+}$, $\mathrm{EC}$, and mineral dust in this region are $23,22,9,7,5$, and $65 \mathrm{\mu g} \mathrm{m}^{-3}$, respectively, which are similar to the HBP value, with slightly higher masses for $\mathrm{SO}_{4}^{2-}$ and $\mathrm{OC}$ and slightly lower values for $\mathrm{NO}_{3}^{-}$and mineral dust. The corresponding winter values are $43,47,23,18,14$, and $145 \mu \mathrm{g} \mathrm{m}^{-3}$. The difference between the winter and background concentrations in the SCB area is very similar to that in the HBP area, thereby showing the relatively polluted condition in this area.

In general, two values of OC/EC were obtained: $\sim 3.1$ in December to January and $\sim 0.41$ in February. The higher $\mathrm{OC} / \mathrm{EC}$ ratio is quite similar to biomass fuel combustion (3.3), and the lower value is close to gasoline (1.4) (Cao et al., 2010). These results suggest the contributions of biomass burning for heating during winter in the SCB area, and the contribution from motor vehicles was also observed. The low $\mathrm{OC} / \mathrm{EC}$ ratio during winter is also similar to most values of $\mathrm{OC} / \mathrm{EC}$ during other seasons, thereby showing the strong influence of motor vehicles on OC and EC in this area.

\section{Summary}

On the basis of mass concentrations of sulfate, OC, nitrate, ammonium, EC, and mineral dust from $24 \mathrm{~h}$ aerosol particles $\left(\mathrm{PM}_{10}\right)$ collected from various CAWNET stations from 2006 to 2013, the change in these major water-soluble constituents, carbonaceous species, mineral aerosols, and $\mathrm{PM}_{10}$ since 2006 and the contribution of meteorological condition have been investigated in this study. The mass concentrations and comparison of the chemical components in major haze regions of China were also provided, with details for 2012 and 2013 in particular, in hopes of strengthen the understanding of the growing haze-fog over the years in China. Moreover, this study can also serve as a basis in chemical composition aspects for further evaluation on the effect of implementation of various pollution control countermeasures after 2013, which is called atmospheric pollution prevention and control of the ten measures of China by Chinese government. This investigation also provides the inputs and validation for a haze-fog forecasting system that has used a lot of near-realtime (NRT) data.

The major findings of this study can be summarized as follows.

During 2013, the mineral aerosol was found still to be the largest component of $\mathrm{PM}_{10}$ in almost all stations in different haze areas, thereby showing the high "dust" characteristics in aerosol pollution of China, in which the contribution of coal ash should not be ignored. Thus, a high mineral concentration was observed even in the southern part of the urban areas in China. The high regional background loading of $90 \mu \mathrm{g} \mathrm{m}^{-3}$ in mineral aerosol was observed in haze region II, which was caused by not only sand-dust-storm dust and urban fugitive dust, but also coal ash that is highly related to the large amount of coal combustion activities in this area. The increased coal ash during winter, which was mainly from the increased coal combustion for heating, could be the reason for higher mass concentrations of mineral dust in winter, which has about 1.5 times higher concentrations of mineral aerosol in winter relative to normal background mean at HBP area $\left(\sim 130 \mu \mathrm{g} \mathrm{m}^{-3}\right)$ (Table 3$)$. This is also true for other haze regions in China with 2 to 3 factors higher mineral dust mass in winter (Table 3).

Sulfate contributed the first and second largest anthropogenic mass fraction to atmospheric aerosol (i.e., 12 to $25 \%$ ) in most of areas of China in 2013, except for rural Northwest China. OC normally ranked third and accounted for about 7 to $19 \%$ by mass, with high proportions in Gucheng and Panyu. The mass fractions of nitrate and ammonium were normally around 5 to $10 \%$ and 3 to $7 \%$, respectively, while in most areas of China, elemental carbon represented 2 to $4 \%$. All these percentage are similar with the results of 2006 and 2007 (X. Y. Zhang et al., 2012).

More than $50 \%$ of primary OC and 28 to $50 \%$ of nitrate mass were attributed to coal combustion in 2013. In the stations of Gucheng, Zhengzhou, and XiAn in HBP, the nitrate concentrations are all higher than or close to those in Beijing, which is the city with the largest number of motor vehicles within haze region II. The result suggests that coal combustion also has an important contribution to the increased nitrate concentrations in this area. $\mathrm{NH}_{4}^{+}$concentrations are much higher in HBP than in other regions, with the background and winter concentrations of 7.5 and $23 \mu \mathrm{g} \mathrm{m}^{-3}$, respectively, which imply that the major sources of $\mathrm{NH}_{4}^{+}$are located in the HBP. Agricultural activity is the most important source of ammonium.

An excessive amount of unclean energy consumption was the most fundamental reason for the increased severity of haze and fog events in China, in which coal combustion was still the largest anthropogenic source for aerosol pollution in various areas of China in 2013. The proportion of each chemical component of $\mathrm{PM}_{10}$ had no evident changes from 2006 to 2013, which also shows that the sources for aerosol particles did not significantly change from 2006 to 2013.

Wintertime mass concentrations of aerosol chemical components and $\mathrm{PM}_{10}$ are more important than annual mean value in evaluating aerosol pollution for a year. In the HBP area, the winter concentrations were usually about $2-4$ factors higher than the normal regional background masses (Table 3), and concentrations in winter for various components normally exhibited a decline during 2006 to 2010 (considered as the first phase for the pollution change during 20062013), and then rose till 2013 (called second phase).

Given the $\sim 25 \%$ increase in $\mathrm{PM}_{10}$ concentrations in January of 2013, relative to 2012 in the HBP area, the winter values of $\mathrm{SO}_{4}^{2-}$ and $\mathrm{NH}_{4}^{+}$concentrations in 2013 increased close 

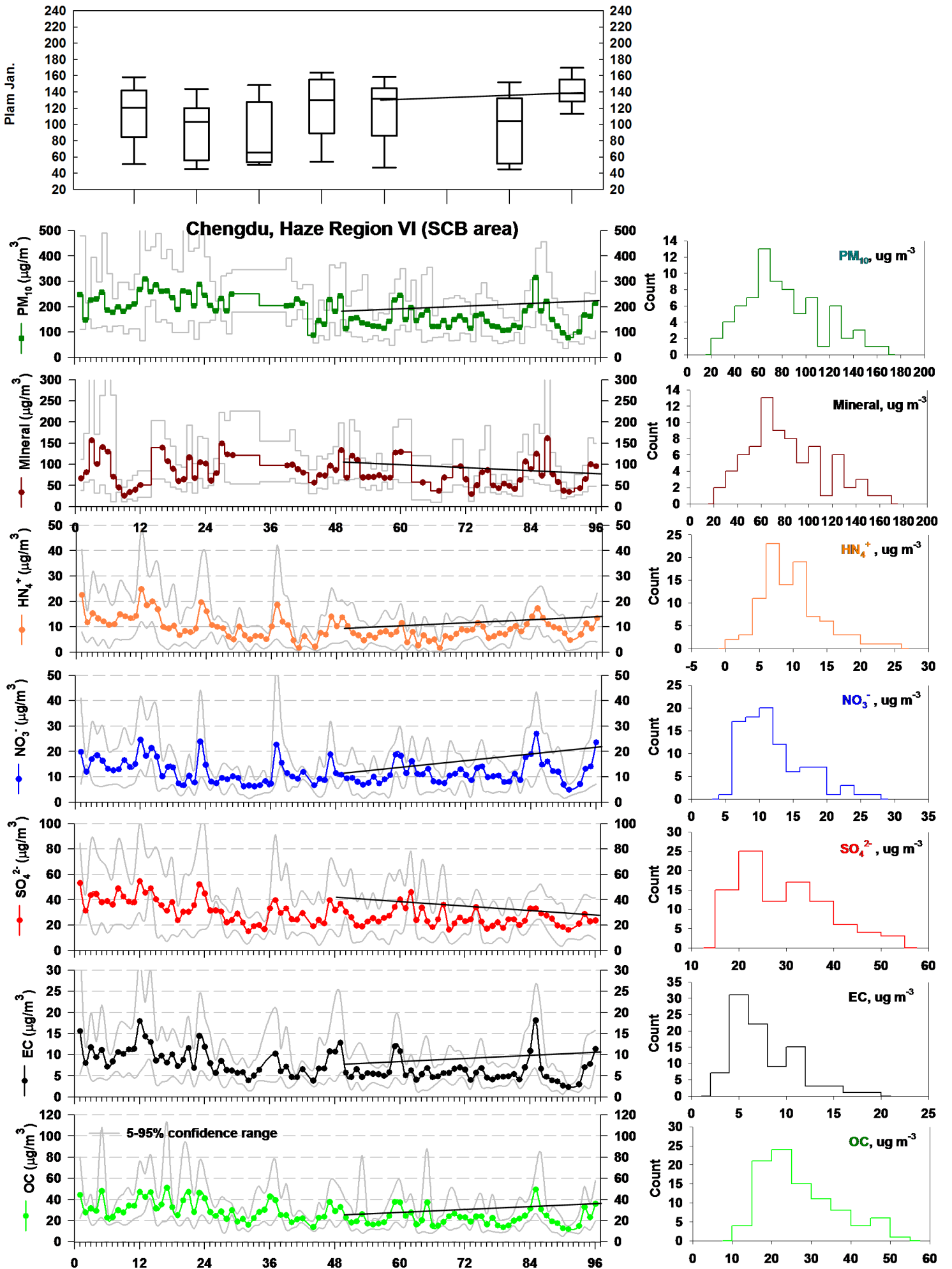

Figure 6. Left panel: change of monthly median concentrations of major chemical components, PM 10 , and January PLAM at Chengdu in haze region VI, one of the major haze region in the Si Chuan Basin (SCB) area in China. Wintertime data were used in linear trend fitting from 2010 to 2013; right panel: histogram analysis result for various chemical components. 
Table 3. Comparisons between normal regional background and winter concentrations $\left(\mu \mathrm{g} \mathrm{m}^{-3}\right)$ for major chemical components of aerosol particles in major haze regions of China.

\begin{tabular}{|c|c|c|c|c|c|c|c|}
\hline Regions & Conditions & $\mathrm{SO}_{4}^{2-}$ & $\mathrm{OC}$ & $\mathrm{NO}_{3}^{-}$ & $\mathrm{NH}_{4}^{+}$ & EC & Mineral aerosol \\
\hline \multirow[t]{2}{*}{ HBP } & Regional background conc. & 20 & 15 & 12 & 7.5 & 5 & 90 \\
\hline & Winter conc. & 43 & 55 & 28 & 23 & 21 & 130 \\
\hline \multirow[t]{2}{*}{ YRD } & Regional background conc. & 17 & 11 & 6 & 6 & 3 & 25 \\
\hline & Winter conc. & 33 & 22 & 15 & 10 & 5 & 65 \\
\hline \multirow[t]{2}{*}{ PRD } & Regional background conc. & 17 & 13 & 9 & 7 & 3.5 & 25 \\
\hline & Winter conc. & 33 & 22 & 15 & 9 & 6.7 & 70 \\
\hline \multirow[t]{2}{*}{ SCB } & Regional background conc. & 23 & 22 & 9 & 7 & 5 & 65 \\
\hline & Winter conc. & 43 & 47 & 23 & 18 & 14 & 145 \\
\hline
\end{tabular}

to or at a factor of 1 in 2013 , relative to 2012. The OC concentrations increased by $\sim 50 \%$. All of these resulted in persistent haze-fog events in Jan. of 2013, which did not happen in the winter of 2012 . About $60 \%$ of this increment can be attributable to worsening meteorological conditions. The Asia Pacific Economic Cooperation (APEC) summit period (810 November 2014) was associated with bad meteorological conditions with 100 to 120 of PLAM at Beijing, an 35\% reduction of pollutant emission in the BIV area by various control measures. This $\sim 35 \%$ cut resulted in good air quality, and was called "APEC blue" in the media (all the details will be introduced in a companion paper separately). From the fact that there was an increment of $\sim 25 \%$, pollutants in the HBP area resulted in persistent haze-fog events in winter 2013 and a cut of $35 \%$ in APEC blue in 2014 winter. One could approximately estimate that there will be no frequent persistent haze-fog event induced by aerosol pollution, if approx. one-third of pollutant emission can be reduced on the basis of winter emission levels of 2013 in BIV. The approx. one-third reduction of 2013 winter emission might be considered as the upper limit of capacity of aerosol pollution in this area.

OC contributed the most in the increase in $\mathrm{PM}_{10}$ concentrations during winter from 2010 to 2013 in the HBP area, in which the contribution from biomass fuel burning for heating was identified in addition to the contribution from the scattered and central coal combustion for heating. The phenomenon was also found in the YRD and SCB areas but not in the PRD area, where the contribution from the coal combustion to various chemical components was noted before 2009, but after 2010 the contributions from motor vehicles increased.

All sulfate data fitting from 2010 to 2013 shows a decreasing trend in the HBP area that is the opposite of the fitting when only wintertime data are used, thereby reflecting the effect of power plant desulfurization since 2002 in China. This is also true for the PRD and SCB areas, but almost no change in the YRD area. Unlike in sulfate, the linear fit using all season nitrate data in the four major haze regions still showed an increasing trend from 2010 to 2013, thereby par- tially showing the lack of effect of power plant denitrification. Since large-scale interest on power plant denitrification started in 2012 in China, the effect of desulfurization has not yet been fully expressed. Of course the increased number of motor vehicles and the burning of more natural gas also contributed to the increase in nitrate concentrations over these years.

In haze region III (YRD area), although there were some changes in different chemical components between 2010 and 2013, the $\mathrm{PM}_{10}$ concentrations in the winter remained less changed and are associated with similar changes in PLAM. The regional background concentrations of $\mathrm{SO}_{4}^{2-}, \mathrm{OC}, \mathrm{NO}_{3}^{-}$, $\mathrm{NH}_{4}^{+}, \mathrm{EC}$, and mineral dust are normally 2 to 2.6 factors less than winter high values for each of them (Table 3 ). The weak influence of winter heating was identified in this area.

In haze region V (PRD area), the pollution-meteorological conditions during winter were much better than that in the HBP, and continually improved from 2010 to 2013. This improvement is associated with a decline in almost all chemical components and $\mathrm{PM}_{10}$ during winter, with less change for nitrate. This trend is the opposite of that in HBP. Within the same haze region $\mathrm{V}$, nitrate mass was a factor higher in Panyu of Guangdong province than in Nanjing of Guangxi province, thereby showing a relatively larger influence of motor vehicles and natural gas burning on nitrate concentrations in Panyu compared with that in Nanjing. Similar to the mass and difference between winter and normal conditions in the YRD area, the regularly observed background concentrations of $\mathrm{SO}_{4}^{2-}, \mathrm{OC}, \mathrm{NO}_{3}^{-}, \mathrm{NH}_{4}^{+}$, and $\mathrm{EC}$ are normally 1-3 factors lower than winter higher values for each of them (Table 3).

In haze region VI (SCB area), the background and higher concentrations of chemical components and $\mathrm{PM}_{10}$ in winter were all similar to those of the HBP, with background masses 2-3 factors lower than winter concentrations for $\mathrm{SO}_{4}^{2-}, \mathrm{OC}$, $\mathrm{NO}_{3}^{-}, \mathrm{NH}_{4}^{+}, \mathrm{EC}$, and mineral dust (Table 3). During the winter, the contributions of biomass fuel burning from heating to $\mathrm{OC}$ and EC were also identified in this area, and the contribution from motor vehicles also observed in other parts of wintertime and other season. The change in chemical com- 
ponents in January and the associated changes in PLAM in the SCB area were similar to those in the YRD area, with a slight change in winter, 130 of PLAM, for aerosol pollution from 2010 to 2013.

Evidence of comparisons for the chemical components in $\mathrm{PM}_{10}$ and $\mathrm{PM}_{2.5}$ in Beijing suggests that the secondary aerosol particle (sulfate, nitrate, ammonium, SOC) and particles from combustion (EC and POA) are closely associated with the particles with diameters smaller than $2.5 \mu \mathrm{m}$. The measurement of $\mathrm{PM}_{10}$ from monitoring or filter analysis can provide information that covers all kinds of information related to chemical components of $\mathrm{PM}_{2.5}$ and also includes information about mineral dust, especially those with diameters between 2.5 and $10 \mu \mathrm{m}$, which can fully reflect the problems of aerosol pollution in China.

Acknowledgements. This research was supported by grants from National Key Project of Basic Research (2011CB403401) and Specific Team Fund of the Jiangsu Collaborative Innovation Center for Climate Change. We sincerely thank the support of aerosol sampling from CAWNET staffs of CMA.

Edited by: S. Gong

\section{References}

Boucher, O., Randall, D., Artaxo, P., Bretherton, C., Feingold, G., Forster, P., Kerminen, V.-M., Kondo, Y., Liao, H., Lohmann, U., Rasch, P., Satheesh, S. K., Sherwood, S., Stevens, B., and Zhang, X. Y.: Clouds and aerosols, in: Climate change 2013: The physical science basis. Contribution of working group i to the fifth assessment report of the intergovernmental panel on climate change, edited by: Stocker, T. F., Qin, D., Plattner, G.-K., Tignor, M., Allen, S. K., Boschung, J., Nauels, A., Xia, Y., Bex, V. and Midgley, P. M., Cambridge University Press, New York, 2013.

Cao, G., Zhang, X., and Zheng, F.: Inventory of black carbon and organic carbon emissions from china, Atmos. Environ., 40, 65166527, 2006.

Cao, G. L., An, X. Q., Zhou, C. H., Ren, Y. Q., and Tu, J.: Emission inventory of air pollutants in china, China Environ. Sci., 30, 900906, 2010.

Chow, J. C., Watson, J. G., Pritchett, L. C., Pierson, W. R., Frazier, C. A., and Purcell, R. G.: The dri thermal/optical reflectance carbon analysis system: Description, evaluation and applications in u.S. Air quality studies, Atmos. Environ. A, 27, 1185-1201, 1993.

Chow, J. C., Watson, J. G., Chen, L.-W. A., Arnott, W. P., Moosmüller, H., and Fung, K. K.: Equivalence of elemental carbon by thermal/optical reflectance and transmittance with different temperature protocols, Environ. Sci. Technol., 38, 4414-4422, 2004.

Donkelaar, A. V. and Villeneuve, P. J.: Global estimates of ambient fine particulate matter concentrations from satellite-based aerosol optical depth: Development and application, Environ. Health Persp., 118, 847-855, 2010.
Forster, P., Ramaswamy, V., Artaxo, P., Berntsen, T., Betts, R., Fahey, D. W., Haywood, J., Lean, J., Lowe, D. C., Myhre, G., Nganga, J., Prinn, R., Raga, G., Schulz, M., and Dorland, R. $\mathrm{V}$.: Changes in atmospheric constituents and in radiative forcing [m]//ipcc, in: Climate Change 2007: the Physical Science Basis, contribution of Working Group I to the Fourth Assessment Report of the Intergovernmental Panel on Climate Change, edited by: Solomon, S., Qin, D., Manning, M., Chen, Z., Marquis, M., Averyt, K. B., Tignor, M., and Miller, H. L., Cambridge University Press, Cambridge, UK and New York, USA, 153-171, 2007

Gao, S., Wang, X., and Zhou, Y.: Generation of generalized moist potential vorticity in a frictionless and moist adiabatic flow, Geophys. Res. Lett., 31, L12113, doi:10.1029/2003GL019152, 2004.

Göke, S., Schimek, S., Terhaar, S., Reichel, T., Göckeler, K., Krüger, O., Fleck, J., Griebel, P., and Paschereit, C. O.: Influence of pressure and steam dilution on nox and co emissions in a premixed natural gas flame, J. Eng. Gas Turb. Power, 136, GTP14-1050, doi:10.1115/1.4026942, 2014.

Guo, S., Hu, M., Zamora, M. L., Peng, J., Shang, D., Zheng, J., Du, Z., Wu, Z., Shao, M., and Zeng, L.: Elucidating severe urban haze formation in china, P. Natl. Acad. Sci. USA, 111, 17373-17378, 2014.

He, K., Yang, F., Ma, Y., Zhang, Q., Yao, X., Chan, C. K., Cadle, S., Chan, T., and Mulawa, P.: The characteristics of $\mathrm{PM}_{2.5}$ in beijing, china, Atmos. Environ., 35, 4959-4970, 2001.

Hu, M., He, L. Y., Zhang, Y. H., Wang, M., Pyo Kim, Y., and Moon, K. C.: Seasonal variation of ionic species in fine particles at qingdao, Atmos. Environ., 36, 5853-5859, 2002.

Huang, R.-J., Zhang, Y., Bozzetti, C., Ho, K.-F., Cao, J.-J., Han, Y., Daellenbach, K. R., Slowik, J. G., Platt, S. M., and Canonaco, F.: High secondary aerosol contribution to particulate pollution during haze events in china, Nature, 514, 218-222, 2014.

Johnson, A. B. and Baker, D. G.: Climatology of diffusion potential classes for minneapolis-st. Paul, J. Appl. Meteorol., 36, 16201628, 1997.

Li, J., Wang, G., Aggarwal, S. G., Huang, Y., Ren, Y., Zhou, B., Singh, K., Gupta, P. K., Cao, J., and Zhang, R.: Comparison of abundances, compositions and sources of elements, inorganic ions and organic compounds in atmospheric aerosols from xi'an and new delhi, two megacities in china and india, Sci. Total Environ., 476, 485-495, 2014.

Lu, Z., Zhang, Q., and Streets, D. G.: Sulfur dioxide and primary carbonaceous aerosol emissions in China and India, 1996-2010, Atmos. Chem. Phys., 11, 9839-9864, doi:10.5194/acp-11-98392011, 2011.

NBS-Beijing: Beijing statistical yearbook, China Statistics Press, 2013.

NBS-China: China statistical yearbook, China Statistics Press, 2014.

Pang, X., Mu, Y., Lee, X., Zhang, Y., and Xu, Z.: Influences of characteristic meteorological conditions on atmospheric carbonyls in beijing, china, Atmos. Res., 93, 913-919, 2009.

Pérez, C., Nickovic, S., Pejanovic, G., Baldasano, J. M., and Özsoy, E.: Interactive dust-radiation modeling: A step to improve weather forecasts, J. Geophys. Res., 111, 1-17, 2006.

Seinfeld, J. H. and Pandis, S. N.: Atmospheric chemistry and physics: From air pollution to climate change, John Wiley \& Sons, INc., New York, 1997. 
Sui, K., Wang, Z., Yang, J., Xie, F.-Y., and Zhao, Y.: Beijing persistent $\mathrm{PM}_{10}$ pollution and its relationship with general meteorological features, Res. Environ. Sci., 20, 77-83, 2007.

Sun, Y., Jiang, Q., Wang, Z., Fu, P., Li, J., Yang, T., and Yin, Y.: Investigation of the sources and evolution processes of severe haze pollution in beijing in January 2013, J. Geophys. Res.-Atmos., 119, 4380-4398, 2014.

Twomey, S. J.: The influence of pollution on the shortwave albedo of clouds, J. Atmos. Sci., 34, 1149-1152, 1977.

Wang, H., Zhang, X. Y., Gong, S. L., Chen, Y., Shi, G. Y., and Li, W.: Radiative feedback of dust aerosols on the eastasian dust storms, J. Geophys. Res., 115, D23214, doi:23210.21029/22009JD013430, 2010.

Wang, H., An, J., Shen, L., Zhu, B., Pan, C., Liu, Z., Liu, X., Duan, Q., Liu, X., and Wang, Y.: Mechanism for the formation and microphysical characteristics of submicron aerosol during heavy haze pollution episode in the yangtze river delta, China, Sci. Total Environ., 490, 501-508, 2014.

Wang, J. Z., Gong, S., Zhang, X. Y., Yang, Y. Q., Hou, Q., Zhou, C., and Wang, Y.: A parameterized method for airquality diagnosis and its applications, Adv. Meteorol., 1-10, doi:10.1155/2012/238589, 2012.

Wang, X., Chen, J., Sun, J., Li, W., Yang, L., Wen, L., Wang, W., Wang, X., Collett, J. L., and Shi, Y.: Severe haze episodes and seriously polluted fog water in ji'nan, China, Sci. Total Environ., 493, 133-137, 2014.

Wang, Y. H., Liu, Z. R., Zhang, J. K., Hu, B., Ji, D. S., Yu, Y. C., and Wang, Y. S.: Aerosol physicochemical properties and implications for visibility during an intense haze episode during winter in Beijing, Atmos. Chem. Phys., 15, 3205-3215, doi:10.5194/acp-15-3205-2015, 2015.

Wang, Z., Li, J., Wang, Z., Yang, W., Tang, X., Ge, B., Yan, P., Zhu, L., Chen, X., and Chen, H.: Modeling study of regional severe hazes over mid-eastern china in january 2013 and its implications on pollution prevention and control, Sci. China Earth Sci., 57, $3-$ 13, 2014.

Watson, J.: Visibility: Science and regulation, J. Air Waste Manage., 52, 628-713, 2002.

Xu, H., Bi, X.-H., Zheng, W.-W., Wu, J.-H., and Feng, Y.-C.: Particulate matter mass and chemical component concentrations over four chinese cities along the western pacific coast, Environ. Sci. Pollut. Res., 22, 1-14, 2014.

Yang, Y.: A plam index forecast method for air quality of beijing in summer, Journal of Applied Meteorological Science, 20, 649655, 2009.

Yao, X., Chan, C. K., Fang, M., Cadle, S., Chan, T., Mulawa, P., He, K., and Ye, B.: The water-soluble ionic composition of $\mathrm{PM}_{2.5}$ in shanghai and beijing, china, Atmos. Environ., 36, 4223-4234, 2002 .
Ye, B., Ji, X., Yang, H., Yao, X., Chan, C. K., Cadle, S. H., Chan, T., and Mulawa, P. A.: Concentration and chemical composition of $\mathrm{PM}_{2.5}$ in shanghai for a 1-year period, Atmos. Environ., 37, 499-510, 2003.

Yin, L., Niu, Z., Chen, X., Chen, J., Xu, L., and Zhang, F.: Chemical compositions of $\mathrm{PM}_{2.5}$ aerosol during haze periods in the mountainous city of yong'an, China, J. Environ. Sci., 24, 1225-1233, 2012.

Zhang, X., Arimoto, R., An, Z., Chen, T., Zhu, G., and Wang, X.: Atmospheric trace elements over source regions for chinese dust: Concentrations, sources and atmospheric deposition on the loess plateau, Atmos. Environ., 27, 2051-2067, 1993.

Zhang, X., Zhang, Y., and Cao, G.: Aerosol chemical compositions of beijing $\mathrm{PM}_{1}$ and its control countermeasures, Journal of Applied Meteorological Science, 23, 257-264, 2012 (in Chinese with English abstract).

Zhang, X., Sun, J., Wang, Y., Li, W., Zhang, Q., Wang, W., Quan, J., Cao, G., Wang, J., Yang, Y., and Zhang, Y.: Factors contributing to haze and fog in china, Chinese Sci. Bull., 58, 1178-1187, doi:10.1360/972013-150, 2013 (in Chinese).

Zhang, X. Y., Cao, J. J., Li, L. M., Arimoto, R., Cheng, Y., Huebert, B., and Wang, D.: Characterization of atmospheric aerosol over xian in the south margin of the loess plateau, china, Atmos. Environ., 36, 4189-4199, 2002.

Zhang, X. Y., Gong, S. L., Shen, Z. X., Mei, F. M., Xi, X. X., Liu, L. C., Zhou, Z. J., Wang, D., Wang, Y. Q., and Cheng, Y.: Characterization of soil dust aerosol in china and its transport/distribution during 2001 ace-asia. 1. Network observations, J. Geophys. Res, 108, 4261, doi:10.1029/2002JD002632, 2003.

Zhang, X. Y., Wang, Y. Q., Zhang, X. C., Guo, W., and Gong, S. L.: Carbonaceous aerosol composition over various regions of china during 2006, J. Geophys. Res, 113, D14111, doi:10.1029/2007JD009525, 2008.

Zhang, X. Y., Wang, Y. Q., Lin, W. L., Zhang, Y. M., Zhang, X. C., Gong, S., Zhao, P., Yang, Y. Q., Wang, J. Z., Hou, Q., Zhang, X. L., Che, H. Z., Guo, J. P., and Li, Y.: Changes of atmospheric composition and optical properties over beijing 2008 olympic monitoring campaign, B. Am. Meteorol. Sci., 1634-1651, 2009.

Zhang, X. Y., Wang, Y. Q., Niu, T., Zhang, X. C., Gong, S. L., Zhang, Y. M., and Sun, J. Y.: Atmospheric aerosol compositions in China: spatial/temporal variability, chemical signature, regional haze distribution and comparisons with global aerosols, Atmos. Chem. Phys., 12, 779-799, doi:10.5194/acp12-779-2012, 2012

Zhang, X. Y.: Characteristics of the chemical components of aerosol particles in the various regions over china, Acta Meteorol. Sin., 72, 1-11, doi:10.11676/qxxb2014.062, 2014 (in Chinese). 